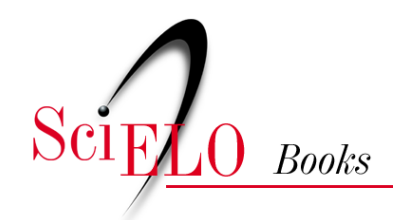

EdUfSCar

\title{
1 - Dinâmica molecular de born-oppenheimer: Metodologia e aplicações em mecanismos e seletividades de reações químicas
}

\author{
Miguel Angelo F. de Souza \\ Ricardo L. Longo
}

\section{SciELO Books / SciELO Livros / SciELO Libros}

SOUZA, M.A.F., and LONGO, R.L. Dinâmica molecular de Born-oppenheimer: metodologia e aplicações em mecanismos e seletividades de reações químicas. In: FREITAS, L.C.G., and OLIVEIRA, G.S., orgs. Aplicações de química teórica no estudo de materiais: métodos in silico para nanomateriais [online]. São Carlos: EdUFSCar, 2018, pp. 14-61. ISBN 978-65-80216-12-3. Avalaible from: doi: 10.7476/9786580216123.0002. Also available in ePUB from: http://books.scielo.org/id/nvnjd/epub/freitas-9786580216123.epub.

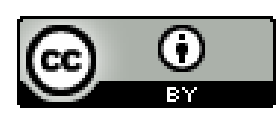

All the contents of this work, except where otherwise noted, is licensed under a Creative Commons Attribution 4.0 International license.

Todo o conteúdo deste trabalho, exceto quando houver ressalva, é publicado sob a licença Creative Commons Atribição 4.0. 


\section{DINÂMICA MOLECULAR DE BORN-OPPENHEIMER}

metodologia e aplicações em mecanismos e seletividades de reações químicas

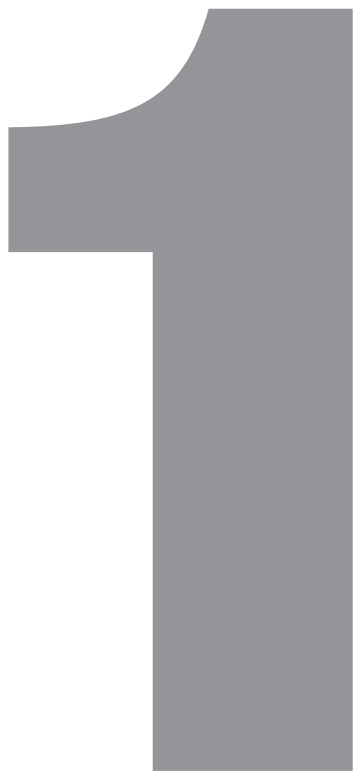

Miguel Angelo F. de Souza ${ }^{1}$ e Ricardo L. Longo²

\footnotetext{
1 Departamento de Química Fundamental da Universidade Federal de Pernambuco (UFPE), Recife-PE. Instituto de Química da Universidade Federal do Rio Grande do Norte (UFRN), Natal-RN. E-mail: <migranthy@yahoo.com.br>.

2 Departamento de Química Fundamental da UFPE. E-mail: <longo@ufpe.br>.
} 


\subsection{INTRODUÇ̃̃̃ $0^{3}$}

Nas duas últimas décadas, os aprimoramentos do desempenho computacional e os desenvolvimentos de algoritmos e métodos eficientes tornaram possíveis as investigações computacionais dos mecanismos de reações com métodos de dinâmica molecular direta ou on the fly, também denominada dinâmica molecular de Born-Oppenheimer. ${ }^{4}$ Essa área está alcançando grande importância e relevância em química teórica/computacional, pois permite interpretar e prever mecanismos e seletividades de reações químicas em escala atômico-molecular, fornecendo, por exemplo, informações inacessíveis ou muito difíceis de serem obtidas experimentalmente, bem como tem facilitado a interpretação de experimentos de dinâmica de reações.

De fato, a dinâmica direta tem sido utilizada em vários estudos para interpretar resultados experimentais de espalhamentos reativos e, assim, descobrir novos mecanismos de reações ${ }^{5}$ e racionalizar as seletividades que apresentam controles não convencionais. ${ }^{6}$ Mais amplamente, esses métodos têm facilitado a compreensão das dinâmicas de reações químicas, o que está permitindo mostrar as limitações de teorias consagradas, como a teoria do estado de transição (TST, do inglês Transition State Theory) e a teoria RRKM, ${ }^{7}$ e da aproximação estática, como a coordenada de reação intrínseca (IRC, do inglês Intrinsic Reaction Coordinate). ${ }^{8}$

Duas aproximações de dinâmica molecular direta se destacam nos estudos de reações químicas, a saber: a dinâmica molecular de Born-Oppenheimer (BOMD,

\footnotetext{
3 Os autores agradecem às agências de fomento CNPq, CAPES, FACEPE e Finep, além do inct-InAmi e Pronex-FaCEPe-CNPq (APQ-0859-1.06/08), pelos auxílios financeiros, aos CENAPAD-PE e CENAPAD-CE pela disponibilidade computacional, assim como ao Departamento de Química Fundamental da UFPE pelo ambiente de trabalho.

4 Paranjothy et al. (2012).

5 Mikosch et al. (2008).

6 Manikandan, Zhang e Hase (2012).

7 Rehbein e Carpenter (2011), Bachrach (2007), Carpenter (1992, 1998, 2005), Hase (1994).

8 Ammal et al. (2003), Sun, Song e Hase (2002).
} 
do inglês Born-Oppenheimer Molecular Dynamics $)^{9}$ e a dinâmica molecular de Car-Parrinello (CPMD, do inglês Car-Parrinello Molecular Dynamics). ${ }^{10}$ As simulações realizadas com BOMD são semelhantes às de dinâmica molecular clássica tradicional, exceto pela necessidade de cálculos quânticos da estrutura eletrônica. Nessa dinâmica, em cada passo de integração da trajetória, a energia potencial, seu gradiente (primeira derivada) e, às vezes, até sua hessiana (segunda derivada) são calculados com métodos de estrutura eletrônica. Já na CPMD, equações de movimento fictícias para os orbitais moleculares (ou os orbitais de Kohn-Sham) são propagadas simultaneamente com as equações de movimento clássicas para os núcleos.

As vantagens e desvantagens da propagação de trajetórias usando as técnicas BOMD e CPMD são ainda tema de investigação da comunidade científica especializada. ${ }^{11}$ No entanto, a desvantagem principal do método CPMD, já relatada na literatura, está relacionada ao fato de um possível fluxo de energia a partir das coordenadas nucleares para os graus de liberdade eletrônicos (fictícios) e vice-versa, ${ }^{12} \mathrm{o}$ que pode levar a resultados não físicos, pois, dentre outros problemas, essas trocas de energia não são quantizadas. Tem sido relatado na literatura que CPMD é mais eficiente computacionalmente que BOMD, ${ }^{13}$ pois, na CPMD, não é necessário recalcular a função de onda em cada passo de integração da trajetória. No entanto, precauções devem ser tomadas quando se buscam resultados precisos e livres de efeitos não físicos com CPMD, pois tem sido mostrado que, geralmente, é necessário tornar a massa fictícia $(\mu)$ associada aos graus de liberdade eletrônicos infinitesimal para obter resultados adequados. ${ }^{14}$ Entretanto, valores muito pequenos de $\mu$ diminuem o passo de integração, o que causa diminuição significativa da eficiência computacional da CPMD, tornando-a semelhante à BOMD.

Neste capítulo, a metodologia BOMD para simular trajetórias quase clássicas será abordada brevemente e aplicada a dois estudos de mecanismos e seletividades de reações químicas. Mais detalhes sobre as metodologias BOMD e CPMD podem ser encontrados em revisões ${ }^{15}$ e capítulos de livros. ${ }^{16}$

\subsection{BREVE INTRODUÇÃO À METODOLOGIA BOMD}

A dinâmica molecular consiste em tratar os movimentos dos núcleos ou dos átomos classicamente, e suas equações de movimento são resolvidas numericamente, fornecendo suas posições e os momentos com o tempo, isto é, a trajetória. Em

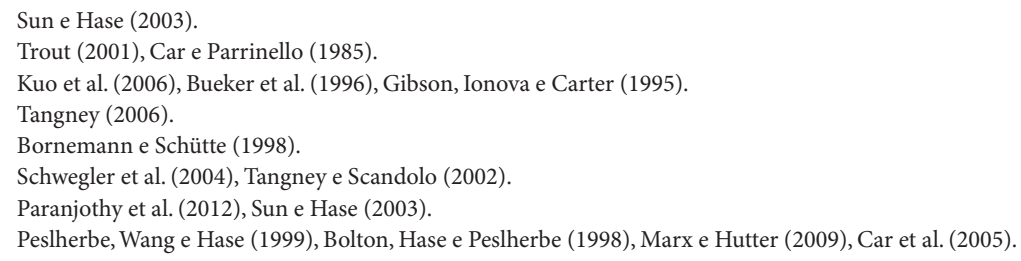


termos matemáticos, isso equivale à resolução das equações de movimento descritas pelas equações de Newton,

$$
m_{i} \frac{\mathrm{d}^{2} q_{i}}{\mathrm{~d} t^{2}}=-\frac{\partial V(q)}{\partial q_{i}}
$$

ou pelas equações de Hamilton,

$$
\frac{\mathrm{d} p_{i}}{\mathrm{~d} t}=-\frac{\partial H}{\partial q_{i}} \text { e } \frac{\mathrm{d} q_{i}}{\mathrm{~d} t}=\frac{\partial H}{\partial p_{i}}
$$

em que $q_{\mathrm{i}}$, $p_{\mathrm{i}}$ e $m_{\mathrm{i}}$ são a coordenada, seu momento conjugado e a massa do átomo $i$, respectivamente; $H$ é a função hamiltoniana dada pela soma da energia cinética e da energia potencial, $V(q)$; e $t$ é a variável tempo.

Em síntese, para resolver as equações de movimento (Equação 1.1 ou 1.2), é necessário responder a três perguntas: (i) como será realizado o procedimento de integração numérica?; (ii) como a energia potencial será calculada?; e (iii) quais serão as condições iniciais do espaço de fase (momento e posição) de cada trajetória? As subseções a seguir discutirão esses assuntos.

As simulações de dinâmica molecular clássicas são comumente conhecidas por aplicações aos sistemas, em que apenas interações descritas por campos de forças entre as partículas (átomos ou grupos de átomos) são suficientes para fornecer várias propriedades de interesse. Por exemplo, propriedades macroscópicas (termodinâmicas) e estruturais podem ser obtidas a partir de simulações atomísticas com base em uma abordagem da mecânica estatística. ${ }^{17}$ No entanto, quando o objetivo é o estudo da dinâmica de reações químicas, é necessária uma descrição quântica que trate adequadamente rearranjos da densidade eletrônica, especialmente aqueles envolvendo a ruptura e a formação de ligações químicas. Na aproximação da dinâmica molecular de Born-Oppenheimer - que é suficiente para se estudar um conjunto amplo de reações térmicas - utiliza-se um método quântico para tratar especificamente a estrutura eletrônica, enquanto a parte nuclear é descrita classicamente. É possível também a utilização de métodos híbridos, como QM/MM (do inglês Quantum Mechanics/ Molecular Mechanics), ${ }^{18}$ ou de extrapolação da energia, como ONIOM, ${ }^{19}$ para estudar reações químicas em fase condensada. Nesses casos, pequenas regiões do sistema associadas à quebra/formação das ligações são tratadas quanticamente, enquanto o restante do sistema e a fase condensada são tratados por campos de força. Portanto, à pergunta do item (ii) acima - como a energia potencial será calculada? - deve-se acrescentar: qual método quântico de estrutura eletrônica será utilizado?

17 Frenkel e Smit (2002), Allen e Tisdesley (1991).

18 Gao (1996).

19 Maseras e Morokuma (1995), Svensson et al. (1996). 


\subsubsection{Integrando as equações de movimento}

Para um dado sistema molecular, o procedimento de integração numérica é comumente realizado em coordenadas cartesianas. Entretanto, é possível realizar esse procedimento nas coordenadas dos modos normais instantâneos. ${ }^{20}$

Independentemente do sistema de coordenadas utilizado, a integração de equações diferenciais, como, por exemplo, a equação 1.1 ou 1.2, é uma área já bem desenvolvida em análise numérica. ${ }^{21}$ Diversos algoritmos são comumente utilizados para integrar numericamente as equações de movimento, por exemplo, Runge-Kutta, Verlet, Adams-Moulton, Gear, predictor-corrector, entre outros. Contudo, tem-se reportado na literatura que a técnica que utiliza o passo de predição e, em seguida, o de correção é um método bastante acurado e pode ser o mais rápido e eficiente, quando conduzido de forma adequada nas coordenadas dos modos normais instantâneos. ${ }^{22}$ De fato, esse esquema tem sido amplamente utilizado em aplicações BOMD nos estudos de diversas reações químicas. ${ }^{23}$ Alguns detalhes do algoritmo predictor-corrector utilizando a aproximação harmônica local serão analisados a seguir. As técnicas associadas à integração numérica utilizando coordenadas cartesianas já estão bem estabelecidas na dinâmica molecular clássica e, portanto, não serão abordadas, pois serão ainda discutidas em outros capítulos deste livro.

\subsubsection{Algoritmo predictor-corrector com base na aproximação harmônica local}

A ideia central da maioria das técnicas de integração numérica que são usadas corriqueiramente em dinâmica molecular direta consiste em ajustar uma superfície modelo na superfície de energia potencial (PES, do inglês Potential Energy Surface), de modo que esta possa ser factível numericamente. Nesse caso, a expansão em série (de potência) de Taylor é utilizada,

$$
f(x)=\sum_{n=0}^{\infty} \frac{f^{(n)}(a)}{n !}(x-a)^{n}
$$

em que $f^{(n)}(a)$ denota a $n$-ésima derivada de $f(x)$ no ponto $a$.

Ao truncar a expansão de Taylor em segunda ordem $(n=2)$, adequando a equação para um sistema molecular genérico e utilizando coordenadas cartesianas (denotadas coletivamente por $q$ ), tem-se a seguinte forma para o potencial:

20 Uggerud e Helgaker (1992), Helgaker, Uggerud e Jensen (1990).

21 Press et al. (1992), Stoer e Bulirsch (1980), Gear (1971).

22 Millam et al. (1999).

23 Paranjothy et al. (2012), Sun e Hase (2003), Peslherbe, Wang e Hase (1999), Bolton, Hase e Peslherbe (1998). 


$$
V(q)=V^{0}+G^{0^{t}} \Delta q+\frac{1}{2} \Delta q^{t} F^{0} \Delta q
$$

em que $V^{0}, G^{0}$ e $F^{0}$ são a energia potencial, o gradiente e a hessiana, respectivamente, na geometria de referência $q^{0} ; \Delta q\left(=q-q^{0}\right)$ são os deslocamentos das coordenadas ao redor dessa geometria; e o sobrescrito $(\ldots)^{t}$ denota a transposta.

Logo, substituindo a Equação 1.4 na Equação 1.1, será obtida a seguinte aproximação para o movimento do $i$-ésimo átomo:

$$
m_{i} \frac{\mathrm{d}^{2} q_{i}}{\mathrm{~d} t^{2}} \cong-\frac{\partial}{\partial q_{i}}\left[V^{0}+G^{0^{t}} \Delta q+\frac{1}{2} \Delta q^{t} F^{0} \Delta q\right]=-G_{i}^{0}-\sum_{j} \mathrm{~F}_{i j}^{0} \Delta q_{j}
$$

Utilizando uma aproximação local harmônica, ou seja, na aproximação das coordenadas dos modos normais instantâneos, as coordenadas cartesianas são transformadas no espaço dos vetores ponderados pela massa, e as equações de movimento aproximadas (1.5) se tornam separáveis, de modo que

$$
\frac{\mathrm{d}^{2} Q_{\alpha}}{\mathrm{d} t^{2}}=-g_{\alpha}-\omega_{\alpha}^{2} Q_{\alpha}
$$

para cada modo normal $\alpha$, em que $Q_{\alpha}$ é correspondente aos deslocamentos dos modos normais, com seus respectivos momentos conjugados $P_{\alpha}$, sendo

$$
\begin{gathered}
Q_{\alpha}=U_{\alpha}^{t} m^{1 / 2} \Delta q \\
g_{\alpha}=U_{\alpha}^{t} m^{1 / 2} G \\
\omega_{\alpha}=U_{\alpha}^{t} m^{1 / 2} \mathrm{Fm}^{1 / 2} U_{\alpha}^{t}=h_{\alpha} \delta_{\alpha \beta}
\end{gathered}
$$

em que $m$ é a matriz diagonal com as massas dos átomos; $U_{\alpha}$ é o autovetor da matriz hessiana; $h_{\alpha}$ é o autovalor correspondente que fornece a frequência angular $\omega_{\alpha}$; e $\delta_{\alpha \beta}$ é o delta de Kronecker.

O conjunto de equações 1.7, 1.8 e 1.9 pode ser resolvido analiticamente, ${ }^{24}$ de modo que as equações de movimento podem ser integradas de acordo com as seguintes condições iniciais: 


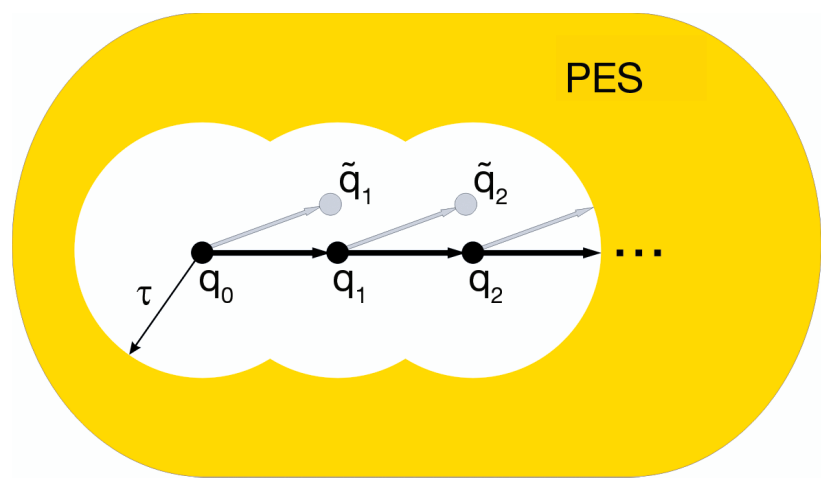

Figura 1.1 Diagrama esquemático do algoritmo predictor-corrector para a integração das equações de movimento em uma trajetória. No passo de predição (seta cinza), a aproximação quadrática é usada no ponto inicial $q_{0}$ para obter o ponto $\tilde{q}_{1}$. Note que esse passo requer um raio de confiança $\tau$. Em seguida, o passo de correção (seta preta) é então realizado na PES, encontrando o ponto $q_{1}$. O procedimento é repetido no novo passo, sendo que o ponto $q_{1}$ é a nova referência para obter $\tilde{q}_{2}$. O procedimento é repetido até o último passo da trajetória.

$$
\begin{array}{ll}
Q_{\alpha}(t)=\frac{P_{\alpha}^{0}}{\omega_{\alpha}} \operatorname{sen}\left(\omega_{\alpha} t\right)-\frac{g_{\alpha}}{\omega_{\alpha}^{2}}\left[1-\cos \left(\omega_{\alpha} t\right)\right] & \omega_{\alpha}>0 \\
Q_{\alpha}(t)=P_{\alpha}^{0} t-\frac{1}{2} g_{\alpha} t^{2} & \omega_{\alpha}=0 \\
Q_{\alpha}(t)=\frac{P_{\alpha}^{0}}{\left|\omega_{\alpha}\right|} \operatorname{senh}\left(\left|\omega_{\alpha}\right| t\right)-\frac{g_{\alpha}}{\left|\omega_{\alpha}\right|^{2}}\left[1-\cosh \left(\left|\omega_{\alpha}\right| t\right)\right. & \omega_{\alpha}<0
\end{array}
$$

e

$$
\begin{array}{ll}
P_{\alpha}^{0}(t)=P_{\alpha}^{0} \cos \left(\omega_{\alpha} t\right)-\frac{g_{\alpha}}{\omega_{\alpha}} \operatorname{sen}\left(\omega_{\alpha} t\right) & \omega_{\alpha}>0 \\
P_{\alpha}^{0}(t)=P_{\alpha}^{0} t-g_{\alpha} t & \omega_{\alpha}=0 \\
P_{\alpha}^{0}(t)=P_{\alpha}^{0} \cosh \left(\left|\omega_{\alpha}\right| t\right)-\frac{g_{\alpha}}{\left|\omega_{\alpha}\right|} \operatorname{senh}\left(\left|\omega_{\alpha}\right| t\right) & \omega_{\alpha}<0
\end{array}
$$

em que $P_{\alpha}{ }^{0}$ é o momento em $t=0$. O procedimento de integração nas coordenadas dos modos normais se torna simples quando os gradientes e as constantes de forças são conhecidos, sendo que para o passo de integração é utilizado o algoritmo predictor-corrector. 
Uma sequência dos passos do algoritmo predictor-corrector está ilustrada na Figura 1.1. Nesta, a primeira etapa é o passo de predição (seta cinza) - nesse passo, a energia potencial, o gradiente e a hessiana são calculados no início $\left(q_{0}\right)$ e no final $\left(\tilde{q}_{1}\right)$. Esses valores são ajustados por uma função polinomial de quarta ou quinta ordem ou por uma função racional, com a finalidade de se obter uma melhor aproximação da PES. Em seguida, ocorre o passo de correção (seta preta, na Figura 1.1), realizado na superfície com o auxílio de um método de integração, como, por exemplo, Bulirsch-Stoer. ${ }^{25}$ Assim, é obtido o ponto corrigido $q_{1}$, que, por sua vez, é agora utilizado como o ponto inicial para o próximo passo de predição $\left(\tilde{q}_{2}\right)$, e o procedimento é então repetido até que o último passo seja alcançado.

Uma das principais vantagens em utilizar coordenadas cartesianas é que a matriz hessiana não é, necessariamente, requerida para o procedimento de integração. Portanto, pergunta-se: qual seria a vantagem de se utilizar a aproximação dos modos normais instantâneos que utiliza a hessiana, sabendo que, em geral, na química quântica, a determinação da hessiana requer elevada demanda computacional (memória RAM e tempo de CPU)? Certamente, a técnica com base na hessiana é mais exata, pois, na aproximação harmônica, o truncamento da série de Taylor é de segunda ordem, e as equações de movimento aproximadas têm soluções analíticas. Além disso, ela pode ser mais rápida e eficiente em alguns casos, pois os passos temporais podem ser maiores e a hessiana pode ser calculada somente após um dado número de passos.

Para qualquer sistema de coordenadas utilizado na dinâmica, a eficiência da integração numérica é limitada, pois um passo pequeno é requerido para manter uma exatidão razoável. Em geral, esse passo é válido somente para uma região pequena ao redor, $q_{0}$ (ilustrativamente, $\tau$, na Figura 1.1, representa o raio de confiança na PES usado no procedimento do passo de integração). Trabalhos descritos na literatura têm demonstrado que a técnica com base na hessiana se torna mais rápida porque o tamanho do passo nas simulações pode ser mais longo, sem comprometer a exatidão dos resultados. Além disso, também tem sido reportado que a matriz hessiana não precisa ser calculada em cada passo, pois, dependendo do sistema, pode-se utilizar a mesma hessiana por vários passos consecutivos da trajetória, o que diminui a demanda computacional, sem comprometer a exatidão. $\mathrm{O}$ número de passos que utiliza a mesma hessiana indica em que intervalo ocorre a sua atualização (do inglês updating the Hessian). ${ }^{26} \mathrm{O}$ acompanhamento da conservação da energia total e do momento angular total é uma forma de verificar se a atualização da hessiana empregada é adequada.

\subsubsection{Comparações entre algoritmos de propagação}

A Tabela 1.1 mostra uma comparação entre os algoritmos de integração usuais, geralmente utilizados na simulação de trajetórias BOMD. As trajetórias

25 Stoer e Bulirsch (1980)

26 Bakken, Millam e Schlegel (1999), Lourderaj et al. (2007). 
simuladas estão associadas à reação de decomposição do formaldeído $\left(\mathrm{H}_{2} \mathrm{CO}\right)$ em di-hidrogênio $\left(\mathrm{H}_{2}\right)$ e monóxido de carbono $(\mathrm{CO})$. As trajetórias são iniciadas na estrutura do estado de transição $\left(\mathrm{H}_{2} \mathrm{CO}^{\ddagger}\right)$ em direção ao produto.

Na Tabela 1.1 apresenta-se o erro médio na energia, durante a integração, e o tempo de CPU requerido para completar a trajetória com os algoritmos de integração: predictor-corrector, velocity-Verlet e Adams-Moulton. Em resumo, o algoritmo predictor-corrector apresenta as melhores relações custo/benefício, ou seja, menor tempo de CPU versus menor erro relativo na energia total durante a trajetória. Para obter o mesmo grau de exatidão, os algoritmos velocity-Verlet e Adams-Moulton requerem três ou quatro vezes mais tempo de CPU quando comparados ao predictor-corrector. Isso ocorre devido ao maior passo temporal utilizado com o algoritmo predictor-corrector, além de ser possível usar um esquema de atualização da Hessiana variando entre cinco e sete passos temporais, sem comprometer a exatidão.

Tabela 1.1 Comparação de integradores com base nos algoritmos predictor-corrector $(\mathrm{p}-\mathrm{c})$, velocity-Verlet (v-V) e Adams-Moulton (A-D) para a reação $\mathrm{H}_{2} \mathrm{CO}^{\ddagger} \rightarrow \mathrm{H}_{2}+\mathrm{CO}$.

\begin{tabular}{|c|c|c|c|c|c|c|c|}
\hline \multirow[b]{2}{*}{ Integrador } & \multirow{2}{*}{$\begin{array}{c}\text { Passo } \\
\text { (fs) }\end{array}$} & \multirow{2}{*}{$\begin{array}{l}\boldsymbol{R}_{\mathrm{c}} \\
(\AA)\end{array}$} & \multirow{2}{*}{$\begin{array}{c}\text { Número } \\
\text { de } \text { update }^{1}\end{array}$} & \multicolumn{2}{|c|}{ Cálculos $^{2}$} & \multirow[b]{2}{*}{$\begin{array}{l}\text { Tempo de } \\
\text { CPU (s) }{ }^{3}\end{array}$} & \multirow{2}{*}{$\frac{\text { Energia }^{4}}{\text { Média do erro (\%) }}$} \\
\hline & & & & Grad. & Hess. & & \\
\hline \multirow[t]{6}{*}{$\mathrm{p}-\mathrm{c}$} & & 0,20 & 5 & 31 & 6 & 173 & $0,08(3)^{5}$ \\
\hline & & 0,20 & 6 & 29 & 5 & 158 & $0,05(3)$ \\
\hline & & 0,20 & 7 & 29 & 4 & 147 & $0,04(3)$ \\
\hline & & 0,25 & 5 & 27 & 5 & 162 & $0,03(3)$ \\
\hline & & 0,25 & 6 & 27 & 4 & 152 & $0,13(3)$ \\
\hline & & 0,25 & 7 & 25 & 4 & 140 & $0,16(3)$ \\
\hline \multirow[t]{3}{*}{$\mathrm{v}-\mathrm{V}$} & 0,1 & & & 240 & & 730 & $0,01(2)$ \\
\hline & 0,2 & & & 120 & & 374 & $0,3(2)$ \\
\hline & 0,4 & & & 60 & & 204 & $1,2(1)$ \\
\hline \multirow[t]{3}{*}{ A-D } & 0,1 & & & 480 & & 1086 & $0,001(4)$ \\
\hline & 0,2 & & & 240 & & 618 & $0,04(3)$ \\
\hline & 0,4 & & & 120 & & 379 & $1,15(1)$ \\
\hline
\end{tabular}

1) Número de atualizações (updates) da hessiana entre os passos da trajetória. 2) Número total de cálculos com o método $\mathrm{HF} / 6-31+\mathrm{G}(\mathrm{d}, \mathrm{p})$, em que os gradientes (grad.) são calculados em cada passo e as hessianas (hess.) estão correlacionadas com o número de atualizações (updates). 3) Tempo de CPU para uma trajetória. 4) Energia total de 17,918 kcal mol ${ }^{-1}$. 5) Número de casas decimais obtido na conservação da energia total, durante a trajetória.

Fonte: adaptada de Lourderaj et al. ${ }^{27}$ 


\subsection{Selecionando a SuPerfície de enerGia POTENCIAL}

Desde o início da década de 1960, simulações de trajetórias clássicas têm sido usadas em estudos da dinâmica de reações químicas. ${ }^{28}$ Tradicionalmente, as simulações das trajetórias com a finalidade de estudar a dinâmica de reações químicas são computadas em PES analíticas predefinidas. ${ }^{29}$ Nessa metodologia, as PES são construídas por funções analíticas empíricas ou, principalmente, por meio de ajustes das energias obtidas com métodos de estrutura eletrônica. Nesse caso, a vantagem principal é que as derivadas do potencial (gradiente e hessiana) são obtidas prontamente. Entretanto, a obtenção de bons resultados se relaciona geralmente com a construção de uma PES com um número muito grande de pontos (dezenas de milhares) e com o ajuste adequado. ${ }^{30}$

Para sistemas reacionais pequenos (com três ou quatro átomos), os resultados da dinâmica obtidos com as PES analíticas se mostram satisfatórios, porém um problema intrínseco surge para sistemas com vários graus de liberdade em razão do significativo aumento do número de cálculos necessários e das variedades topológicas das PES. Na maioria das vezes, deve-se fazer uma separação entre graus de liberdade críticos e não críticos, ou seja, a PES analítica é agora construída a partir de poucas coordenadas escolhidas como as mais importantes entre muitas outras. No entanto, em muitas reações, essa seleção pode ser ambígua e não satisfatória, limitando, assim, o uso dessa metodologia.

Com o aumento da velocidade dos computadores e o aprimoramento e desenvolvimento de novos algoritmos, tornou-se possível o uso dos métodos de estrutura eletrônica diretamente nas simulações de trajetórias clássicas, sem a necessidade de uma construção prévia da PES e, melhor, sem eleger graus de liberdade críticos e realizar ajustes extremamente complexos de superfícies multidimensionais com dezenas de milhares de pontos. Nessa metodologia, as trajetórias são integradas "on the fly" ou "em voo" (durante o movimento), quer dizer, a energia potencial e suas derivadas são obtidas em cada passo da trajetória. Esse tipo de método é conhecido pelo termo "dinâmica direta" ou "on the fly" e foi usado pela primeira vez em 1973, no estudo da reação $\mathrm{CH}_{2}+\mathrm{H}_{2} \rightarrow \mathrm{CH}_{4} \cdot{ }^{31}$

De fato, essa mudança na forma de se obterem as informações da PES nas simulações de trajetórias da dinâmica direta representou talvez o passo mais importante na difusão e popularização dessa técnica na química computacional, a partir de meados de 1990. Com a dinâmica direta, as possíveis diferenças entre os resultados dinâmicos e experimentais não podem necessariamente ser atribuídas à construção inadequada da PES analítica. Atualmente, um dos problemas reside na limitação da exatidão de alguns métodos quânticos.

28 Bunker (1962, 1971), Blais e Bunker (1962).

29 Hirst (1985).

30 Gargano (2003), Murrell et al. (1984).

31 Wang e Karplus (1973). 


\subsubsection{Métodos de estrutura eletrônica}

O objetivo central dos métodos de estrutura eletrônica é obter as soluções da equação de Schrödinger eletrônica (equação 1.12) para determinar, com adequada exatidão, as propriedades de sistemas moleculares, dentro da separação de Born-Oppenheimer:

$$
\hat{\mathrm{H}} \Psi=E \Psi
$$

em que $\hat{H}$ é a parte eletrônica do operador hamiltoniano molecular; $\Psi$ é a função de onda eletrônica; e $E$ é a energia eletrônica.

Geralmente, a solução exata não é factível, tornando necessária a utilização de métodos aproximados. Entre os diversos métodos que podem ser utilizados, o método Hartree-Fock (HF) é o mais popular. Tal método também é conhecido como aproximação do campo médio autoconsistente, termo este que identifica a aproximação principal (campo médio) e o procedimento computacional (autoconsistente). Além de ser capaz de fornecer uma boa solução aproximada (com fins mais qualitativos que quantitativos) para os problemas de muitos elétrons, o método HF tem a vantagem de servir como ponto de partida para outros métodos mais acurados. Esta última característica é a utilidade principal desse método atualmente: seja, por um lado, para métodos semiempíricos - em que são incluídas aproximações adicionais, com o propósito de diminuir a demanda computacional - ou, por outro lado, para os métodos ab initio (pós-HF) - os quais acrescem correções à solução HF, com o intuito de se aproximar da solução exata.

A limitação principal do método HF está no fato de aproximar a função de onda eletrônica por um único determinante de Slater, o que leva ao tratamento do potencial de interação elétron-elétron por um potencial médio efetivo, em que cada elétron interage com o campo médio gerado pelos outros elétrons.

A diferença entre a energia exata não relativística $\left(E_{\text {exata }}\right)$ e a energia $\mathrm{HF}\left(E_{\mathrm{HF}}\right)$ é denominada energia de correlação eletrônica $\left(E_{\text {corr }}\right)$ :

$$
E_{\text {corr }}=E_{\text {exata }}-E_{H F}
$$

Esta é a principal meta dos métodos pós-HF: resgatar ao máximo a $E_{\text {corr }}$.

A seguir, será feita uma breve discussão sobre os métodos de estrutura eletrônica usuais na química computacional, apontando alguns aspectos positivos e negativos sobre cada classe de métodos. Existe uma quantidade enorme de livros (introdutórios ou avançados) que apresentam os métodos de estrutura eletrônica, ${ }^{32}$ assim como há diversas referências (livros, capítulos de livro e artigos) contidas nesses mesmos livros. Obviamente, estes são mais indicados para uma compreensão mais aprofundada sobre os métodos de estrutura eletrônica.

32 Morgon e Coutinho (2008), Jensen (2007), Dykstra et al. (2005), Cramer (2004), Szabo e Ostlund (1989). 


\subsubsection{Métodos pós-HF}

Dois esquemas têm dominado os cálculos pós-HF. De um lado, métodos que usam a combinação linear de determinantes de Slater (configurações), como interação de configurações (CI, do inglês Configuration Interaction), e os métodos do campo autoconsistente com múltiplos determinantes (MCSCF, do inglês Multi-Configurational Self-Consistent Field, e CASSCF, do inglês Complete Active Space $S C F)$; de outro lado estão os métodos de muitos corpos, como a teoria de perturbação (MPn, com $n=2,3$, 4 etc.) e o coupled-cluster (CC). Os primeiros são métodos variacionais, mas não extensivos, e, basicamente, a função de onda $(\mathrm{Y})$ destes pode ser escrita da seguinte forma:

$$
\Psi=\sum_{I}^{N_{\text {conf }}} c_{I} \Phi_{I}=c_{1} \Phi_{1}+c_{2} \Phi_{2}+c_{3} \Phi_{3}+\ldots+c_{N_{\text {conf }}} \Phi_{N_{\text {conf }}}
$$

em que $c_{I}$ é o coeficiente associado à configuração $\Phi_{I}$. A soma é feita sobre as $N_{\text {conf }}$ configurações (excitações) de um estado de referência $\Phi_{0}$, as quais normalmente são escritas por combinações lineares de determinante de Slater. O determinante HF, em geral, é utilizado como a $\left(\Phi_{0}\right)$ referência para a expansão.

A diferença principal entre CI e MCSCF (ou CASSCF) está na determinação variacional dos coeficientes. Na expansão CI, apenas os coeficientes das configurações $\Phi_{I}$ são determinados de maneira variacional, enquanto no MCSCF (ou CASS$\mathrm{CF}$ ), além destes, os coeficientes dos próprios orbitais são também otimizados. Por isso, para fins práticos, o número de determinantes utilizados no método MCSCF (ou CASSCF) deve ser muito menor que no método CI.

Diferentemente, os métodos de muitos corpos não são variacionais, mas são extensivos e apresentam construções bem distintas. O método de perturbação consiste em separar o operador hamiltoniano em uma primeira parte, que possui autofunções conhecidas, e uma parte restante, denominada perturbação. O sucesso desse método está na partição do hamiltoniano tal que a perturbação seja pequena, ou seja, a solução exata seja próxima da solução não perturbada (mas nem sempre isso é possível), de modo que a representação matemática básica é expressa por:

$$
\begin{gathered}
\hat{\mathrm{H}}=\hat{\mathrm{H}}^{(0)}+\lambda V \\
E_{0}=E_{0}^{(0)}+\lambda E_{0}^{(1)}+\lambda^{2} E_{0}^{(2)}+\ldots \\
\Psi_{0}=\Phi_{0}^{(0)}+\lambda \Phi_{0}^{(1)}+\lambda^{2} \Phi_{0}^{(2)}+\ldots
\end{gathered}
$$

em que $\lambda$ é o parâmetro de ordem introduzido para ordenar as correções na energia e na função de onda; $\hat{H}(0)$ é o hamiltoniano de referência (não perturbado); e $V$ é a perturbação. O método perturbativo mais aplicado na química quântica é o Møller-Plessett (MP), em que $\hat{\mathrm{H}}(0)$ é o operador de Fock. Pode-se demonstrar que, para essa partição MP, a correção de primeira ordem é justamente a energia obtida pelo 
método HF, isto é, a energia HF é correta até segunda ordem. Daí, então, tem-se a nomenclatura dos níveis de cálculo da metodologia MPn: MP2, correção de segunda ordem; MP3, correção de terceira ordem; e assim sucessivamente.

O método CC consiste em tratar o sistema com muitos elétrons, separando-os em vários aglomerados (cluster) com poucos elétrons. Basicamente, calculam-se as interações entre os vários elétrons de um mesmo aglomerado e depois entre aglomerados diferentes. O mecanismo matemático que permite essa abordagem é escrever a função de onda coupled-cluster como:

$$
\begin{gathered}
\Psi=e^{T} \Phi_{0} \\
T=T_{1}+T_{2}+T_{3}+\ldots+T_{p} \\
e^{-T} \hat{\mathrm{H}} e^{T} \Psi=E \Psi
\end{gathered}
$$

em que $T$ é denominado operador de cluster e, como mostrado, pode ser escrito em termos dos operadores de substituição simples $\left(T_{1}\right)$ - S, duplas $\left(T_{2}\right)-\mathrm{D}$, triplas $\left(T_{3}\right)$ - T, até $T_{p}$, sendo $p$ o número de elétrons correlacionados. Isso dá origem à seguinte hierarquia, em direção à solução exata: CCS, CCSD, CCSDT, CCSDTQ, e assim sucessivamente. Dada a relação custo/exatidão, o método $\operatorname{CCSD}(\mathrm{T})$ é considerado o estado da arte em estrutura eletrônica de moléculas no estado fundamental.

Além das características computacionais, os métodos de muitos corpos (CC e MP) são extensivos, enquanto os métodos CI e MCSCF (ou CASSCF) não são extensivos. Tem sido reportado na literatura que a falta de extensividade desses métodos pode ser uma limitação importante para sua exatidão.

Por fim, os métodos CI, MP e CC podem ser combinados com uma referência de múltiplos determinantes (MR), gerando, respectivamente, os métodos MRCI (do inglês Multi-Reference Configuration Interaction), MRMP (do inglês Multi-Reference Møller-Plessett) e MRCC (do inglês Multi-Reference Coupled-Cluster). Esses métodos apresentam demanda computacional tão elevada que são praticáveis apenas para sistemas pequenos; no entanto, são, sem dúvida, os métodos mais acurados, principalmente para descrever estados excitados e quebra/formação de ligações.

\subsubsection{Métodos alternativos}

Outras opções de menor custo computacional, comparativamente com os métodos pós-HF, são os métodos de funcionais da densidade e os métodos semiempíricos (estes são muito mais rápidos).

A demanda computacional (tempo de CPU, memória RAM e armazenamento de disco rígido HD) dos cálculos HF tradicionais depende da potência de quarta ordem $\left(\sim M^{4}\right)$ do número de funções de bases $(M)$. Para comparação, o método pós-HF com menor demanda computacional (MP2) tem dependência aproximada de $M^{5}$. Nos métodos semiempíricos, o custo computacional é diminuído pela redução 
do número de integrais. Essa redução é consequência de dois aspectos principais: (i) descrição apenas dos elétrons de valência, com a utilização de base mínima (STO, do inglês Slater Type-Orbitals); e (ii) desprezo das integrais que envolvem produtos entre funções de base em átomos diferentes. Para corrigir essas aproximações (severas), os métodos semiempíricos utilizam parâmetros em suas equações que são ajustados para reproduzir as propriedades moleculares (geometria, entalpia de formação, energia de ionização, momento dipolar, energia de excitação, força de oscilador etc.) de um conjunto de dados experimentais e/ou computacionais.

Os métodos semiempíricos podem ser divididos de acordo com a abordagem teórica, a aplicação da aproximação ZDO (do inglês Zero Differential Overlap), as expressões utilizadas no cálculo das diversas integrais e, por fim, o procedimento de parametrização. A história dos métodos semiempíricos é bastante extensa e acompanha o surgimento da química computacional. Dessa longa história, um número grande de métodos foi criado, porém alguns poucos métodos têm uso difundido atualmente, destacando-se: AM1 (Austin Model 1), PM3 (Parameterized Model Number 3), PM6 (Parameterized Model Number 6) e RM1 (Recife Model 1), para estruturas moleculares e termoquímica de reações; e ZINDO (Zerner's Intermediate Neglect of Differential Overlap), para propriedades espectroscópicas. ${ }^{33}$

O intuito principal de vários métodos semiempíricos é calcular com exatidão adequada diversas propriedades (geometria, entalpia de formação, momento de dipolo etc.) de mínimos locais (reagentes e produtos); entretanto, a caracterização de outros pontos da PES, por exemplo, estados de transição e espécies transientes, pode não ser confiável. Nesses casos, comparações com resultados de métodos ab initio são indispensáveis.

Outra metodologia alternativa que tem aplicação ampla na química computacional são os métodos com base na teoria do funcional da densidade (DFT, do inglês Density Functional Theory). Contrastando com os métodos que procuram aproximações cada vez mais próximas da função de onda exata (todos aqueles pós-HF, além de outros tais como métodos com base na teoria da ligação de valência, em Monte Carlo quântico etc.), a DFT é fundamentada nos teoremas de Hohenberg-Kohn, em que as propriedades moleculares do estado fundamental são determinadas pela densidade eletrônica. Entretanto, o funcional universal da densidade é desconhecido, e, portanto, modelos aproximados são utilizados. A implementação mais utilizada da DFT é a proposta por Kohn e Sham, que descreve o funcional da energia, $E_{\mathrm{KS}}[\rho]$ de um sistema multieletrônico como:

$$
E_{\mathrm{KS}}[\rho]=T_{S}[\rho]+E_{e e}[\rho]+E_{X C}[\rho]
$$

em que $T_{s}[\rho]$ é o funcional da energia cinética de elétrons não interagentes com a mesma densidade $\rho$ do sistema real; $E_{e e}[\rho]$ é o funcional da energia eletrostática; e $E_{X C}[\rho]$ é o funcional da energia de troca-correlação, que inclui, ainda, correções da

33 Morgon e Coutinho (2008), Jensen (2007). 
energia cinética para elétrons interagentes. De fato, este termo, $E_{X C}[\rho]$, é o que diferencia os diversos tipos de métodos DFT. Aproximações como a da densidade local (LDA ou LSD, do inglês Local Density Approximation ou Local Spin Density), a de gradiente generalizado (GGA, do inglês Generalized Gradient Approximation), a conexão adiabática e as parametrizações utilizando dados experimentais podem ser combinadas para tratar o termo $E_{X C}[\rho]$. Todas essas possibilidades levam a centenas de possibilidades, por exemplo, os métodos "puros", descritos pelos funcionais GGA e meta-GGA: B88, BLYP, PW91, PBE etc.; "híbridos" GGA e meta-GGA: B3LYP, PBE1PBE, M06-2X etc.; e "duplo-híbridos": B2PLYP, mPW2PLYP etc., entre inúmeros outros. Os funcionais híbridos utilizam a energia de troca HF como parte do funcional, enquanto os duplo-híbridos incluem ainda a energia de correlação MP2 como parte do funcional. Cabe notar que muitos métodos DFT utilizam parâmetros, universais ou específicos, ajustados a conjuntos de dados selecionados.

Do ponto de vista prático, a demanda computacional dos métodos DFT (exceto duplo-híbridos) é similar ao método HF $\left(\sim M^{4}\right)$, no entanto incluem efeitos de correlação eletrônica. Isso faz com que esses métodos tenham aplicações largamente difundidas nos estudos computacionais de diversos tipos de propriedades de moléculas (isoladas ou em fase condensada) e sólidos.

\subsubsection{Métodos para simulação de trajetórias quase clássicas em dinâmica direta}

A escolha do método de estrutura eletrônica a ser aplicado em dinâmica direta deve tomar como base os seguintes aspectos: (i) o número de trajetórias desejado; e (ii) o passo temporal de integração de cada trajetória.

Uma única trajetória indica apenas um caminho dentre vários, em que os reagentes podem evoluir para os produtos. Portanto, para uma descrição adequada da dinâmica de uma reação, deve-se realizar um conjunto de trajetórias contendo algumas centenas ou milhares de trajetórias, dependendo do objetivo da simulação. Considerando que o passo temporal da integração numérica nas simulações das trajetórias quase clássicas (ou semiclássicas) no estudo de reações químicas é tipicamente $\Delta t=10^{-16} \mathrm{~s}$, têm-se, então, no mínimo, $10^{4}$ cálculos da energia e suas derivadas (gradiente e hessiana) para uma trajetória de $1 \mathrm{ps}\left(10^{-12} \mathrm{~s}\right)$. Caso um conjunto pequeno de 100 trajetórias seja aceitável, então, ao todo, na simulação, serão necessários $10^{6}\left(=10^{4} \times 100\right)$ cálculos de estrutura eletrônica.

Portanto, nas simulações de dinâmica direta para o estudo de reações químicas, a escolha do método de estrutura eletrônica desempenha papel fundamental, implicando na possibilidade ou não de realizar as simulações em tempo hábil. Como visto nas subseções anteriores, o número de métodos de estrutura eletrônica é enorme. Logo, a escolha dos métodos de estrutura eletrônica para realizar as simulações vai, geralmente, depender da relação custo/benefício, ou seja, demanda computacional versus exatidão. Os métodos pós-HF, particularmente os métodos 
MR-CISD, MRMP e CCSD(T), apresentam alta exatidão e alta demanda computacional. Diferentemente, métodos como funcionais da densidade e semiempíricos são conhecidos pela menor demanda computacional, porém é necessário ter garantias (que algumas vezes não são possíveis de se obter) da aplicabilidade com sucesso desses métodos em tipos específicos de propriedades e sistemas moleculares.

Um procedimento que tem dominado a aplicação dos métodos DFT e ab initio em dinâmica direta é validar métodos de menor demanda computacional, ou seja, encontrar uma combinação do método DFT ou ab initio (HF, CASSCF e MP2) com um conjunto pequeno de funções de base que seja adequada para descrever as principais propriedades de interesse da reação. ${ }^{34} \mathrm{O}$ procedimento de validação, geralmente, consiste em descrever as propriedades estruturais e energéticas dos pontos estacionários da reação e, possivelmente, da IRC, com métodos de referência (CCSD(T), MRMP2, MRCISD), e comparar as descrições com os métodos de menor demanda. Portanto, a principal finalidade é eleger o método com menor demanda e mais exato para ser utilizado nas simulações das trajetórias na dinâmica.

Os métodos semiempíricos já foram bastante usados em dinâmica direta, principalmente na década de 1990, quando simulações BOMD de reações químicas começaram a se tornar populares. Entretanto, diferentemente dos métodos DFT e $a b$ initio, a aplicação desses métodos geralmente está associada a um procedimento de reparametrização do método para descrever a reação de interesse. Como já mencionado, o intuito principal dos métodos semiempíricos é calcular diversas propriedades (estrutura, entalpia de formação, momento de dipolo etc.) de mínimos locais (reagentes, intermediários e produtos) com adequada exatidão. No entanto, outros pontos da PES, por exemplo, estados de transição, espécies transientes e complexos intermoleculares, podem não ser confiáveis. Logo, essa deficiência dos métodos semiempíricos em caracterizar adequadamente regiões relevantes da PES, particularmente no que se refere a um mecanismo de reação, faz com que seu uso em dinâmica direta seja muito limitado.

Então, Rossi e Truhlar ${ }^{35}$ sugeriram que os métodos semiempíricos poderiam ser ajustados ou reparametrizados, a partir de dados ab initio obtidos com métodos de referência, para se estudarem reações específicas. Assim, esse método semiempírico reparametrizado poderia descrever com maior precisão os aspectos e as características de uma PES ab initio de uma reação específica. Esse método é conhecido como SRP (do inglês Specific Reaction Parameters). Uma grande variedade de estudos de dinâmica molecular direta tem utilizado o procedimento SRP - uma lista ampla pode ser obtida em Bolton, Hase e Peslherbe. ${ }^{36}$ Características em comum dessas aplicações de dinâmica direta são os estudos detalhados de mecanismos e das seletividades de reações com centenas e/ou milhares de trajetórias simuladas.

\footnotetext{
34 Quijano e Singleton (2011), Goldman, Glowacki e Carpenter (2011), Glowacki, Marsden e Pilling (2009), Gunaydin e Houk (2008), Hamaguchi et al. (2007), Liu et al. (2004), Singleton et al. (2003), Mann e Hase (2002).

35 Rossi e Truhlar (1995).

36 Bolton, Hase e Peslherbe (1998).
} 


\subsubsection{Condições iniciais das trajetórias}

Uma trajetória, isto é, a dependência temporal das posições e dos momentos dos átomos em uma dinâmica, é calculada integrando as equações de movimento a partir de certas condições iniciais. A trajetória pode ser comparada a um filme, cujo fotograma $j$ contém a posição e o momento de todos os átomos no tempo $t$. Portanto, a sucessão de fotogramas pode gerar um "espetáculo" de moléculas evoluindo com o passar do tempo.

Uma única trajetória indica apenas um caminho dentre vários, em que os reagentes podem evoluir para os produtos, tendo, portanto, valor limitado em termos mecanísticos e de seletividade. Logo, um conjunto (ensemble) de trajetórias deve ser obtido de modo estatisticamente relevante, para prover uma visão mais detalhada e coerente do sistema reacional. Tipicamente, uma simulação de dinâmica molecular terá centenas ou milhares de trajetórias, dependendo do tipo de propriedade e refinamento de detalhes desejados. Por exemplo, para o estudo da seletividade de canais em um sistema reativo de interesse, um conjunto de uma ou duas centenas de trajetórias pode ser representativo; ${ }^{37}$ porém, para a determinação de constantes de velocidade com adequada exatidão, o número de trajetórias pode facilmente chegar a milhares. ${ }^{38}$ Entretanto, poucas dezenas de trajetórias podem ser simuladas se uma interpretação limitada é aceitável, como, por exemplo, em colisões reativas entre feixes moleculares com energias e orientações bem estabelecidas. ${ }^{39}$

As trajetórias podem, em princípio, ser iniciadas a partir de qualquer ponto da PES. Por se tratar de equações diferenciais de segunda ordem (ou dois conjuntos de equações diferenciais de primeira ordem), para se iniciar uma dinâmica, são necessários a geometria inicial do sistema, isto é, as coordenadas iniciais dos átomos, e seus respectivos momentos (conjugados). Essa última parte da inicialização pode ser feita de várias formas, as quais têm dependência com o tipo de reação que se está simulando: unimolecular, bimolecular, gás-superfície, entre outros. Os aspectos básicos dos procedimentos de inicialização de trajetórias associadas a reações unimoleculares, bimoleculares e a partir do estado de transição serão discutidos a seguir. Mais detalhes, incluindo outros tipos de situações químicas em procedimento de inicialização de trajetórias, podem ser encontrados nas revisões e capítulos de $\operatorname{livros}^{40}$ e suas diversas referências.

37 Quijano e Singleton (2011), Sun, Song e Hase (2002).

38 Sun e Hase (2004).

39 Mikosch et al. (2008).

40 Paranjothy et al. (2012), Sun e Hase (2003), Peslherbe, Wang e Hase (1999), Bolton, Hase e Peslherbe (1998). 


\subsubsection{Reações unimoleculares}

Para que uma reação unimolecular ocorra, é necessário que o reagente seja excitado com uma energia acima de um limiar - este sendo geralmente associado ao estado de transição - para que possa evoluir para os produtos. Uma teoria amplamente difundida e bem aceita na descrição das reações unimoleculares é a RRKM,${ }^{41}$ em que a constante de velocidade $k(E)$ de uma reação unimolecular pode ser estimada a partir de um conjunto microcanônico dos estados dos reagentes.

A teoria RRKM é fundamentada nas seguintes suposições: (i) colisões entre as próprias moléculas da amostra, com gás inerte ou por absorção de fótons levam uma molécula reagente a obter uma energia interna, $E$, distribuída nos graus de liberdade rotacionais e vibracionais, resultando em uma molécula com energia para reagir; (ii) essa energia interna é distribuída estatisticamente em todos os graus de liberdade, em um tempo relativamente curto, comparado com o tempo de reação, até que uma quantidade suficiente é acumulada em um modo crítico denominado TS; e (iii) a constante de velocidade $k(E)$ é dependente da energia interna da molécula de reagente e é determinada considerando que não há recruzamento através do TS. Essa última suposição é o equivalente dinâmico em assumir que os estados (reagente e TS) estão em equilíbrio.

De fato, essa suposição fundamental da teoria RRKM implica que o movimento clássico do reagente é suficientemente caótico para manter o conjunto microcanônico dos estados. Essa suposição é frequentemente referida como a rápida redistribuição intramolecular da energia vibracional. A identificação de reações que não segue esse tipo de comportamento - não RRKM ou não estatístico - tem dominado os estudos da dinâmica de reações unimoleculares. ${ }^{42}$ Para isso, a dinâmica requer que a seleção das condições iniciais do espaço de fase (momento e coordenada) seja fundamentada em uma amostragem microcanônica dos estados associados aos graus de liberdade rotacionais e vibracionais.

Uma amostragem microcanônica bastante utilizada é fundamentada no hamiltoniano do oscilador harmônico e rotor rígido. Nesse procedimento, supõe-se que um conjunto microcanônico pode ser amostrado pela representação de uma molécula energizada, isto é, um rotor rígido simétrico com $3 N-6$ modos normais, em que $N$ é o número de átomos. O hamiltoniano dessa molécula é a soma das energias do oscilador harmônico, $E_{\mathrm{v}}$, e do rotor rígido simétrico, $E_{\mathrm{r}}$, sem os termos de acoplamento rotovibracional:

$$
H=E=E_{r}+E_{v}
$$

41 Baer e Hase (1999).

42 Lourderaj e Hase (2009), Carpenter (2003, 2005). 


$$
\begin{gathered}
E_{v}=\sum_{\alpha=1}^{3 N-6} \varepsilon_{\alpha}=\sum_{\alpha=1}^{3 N-6} \frac{P_{\alpha}^{2}+\omega_{\alpha}^{2} Q_{\alpha}^{2}}{2} \\
E_{r}=\frac{J(J+1) \hbar^{2}}{2 I_{x}}+\frac{\mathrm{K}^{2} \hbar^{2}}{2}\left(\frac{1}{I_{z}}-\frac{1}{I_{\mathrm{x}}}\right)
\end{gathered}
$$

em que $P_{\alpha}, Q_{\alpha}$ e $\omega_{\alpha}$ é o momento (conjugado), a coordenada e a frequência angular, respectivamente, do modo normal $\alpha$; $J$ e $K$ são os números quânticos rotacionais; $I_{x}$ e $I_{z}$, as componentes do momento de inércia ao longo dos eixos principais do rotor simétrico; e $\hbar=h / 2 \pi$, sendo $h$ a constante de Planck.

Para formar o conjunto microcanônico, valores aleatórios de $P_{\alpha}$ e $Q_{\alpha}$ são escolhidos de modo que exista uma distribuição uniforme no espaço de fase clássico de $H(P, Q)$. A metodologia usual para realizar a distribuição é com base na amostragem de Monte Carlo. ${ }^{43}$ Por exemplo, para gerar uma distribuição uniforme, as energias dos modos normais, $\varepsilon_{\alpha}$, são selecionadas de acordo com Hase e Buckowski: ${ }^{44}$

$$
\varepsilon_{\alpha}=\left[E_{v}-\sum_{\beta=1}^{\alpha-1} \varepsilon_{\beta}\right]\left(1-R_{\alpha}^{\frac{1}{(n-\alpha)}}\right)
$$

em que $R_{\alpha}$ é um número aleatório uniforme entre 0 e 1 , e $n$ é o número de modos normais. Além disso, um segundo número aleatório $R_{\alpha}$ 'é escolhido para designar as fases de cada modo vibracional.

$$
\begin{gathered}
Q_{\alpha}=\left[\frac{\sqrt{2 \varepsilon_{\alpha}}}{\omega_{\alpha}}\right] \cos \left(2 \pi R_{\alpha}{ }^{\prime}\right) \\
P_{\alpha}=-\sqrt{2 \varepsilon_{\alpha}} \operatorname{sen}\left(2 \pi R_{\alpha}^{\prime}\right)
\end{gathered}
$$

Para os números quânticos rotacionais $J$ e $K$, o procedimento para gerar uma distribuição aleatória uniforme é similar ao descrito para os modos normais.

Esse tipo de amostragem aleatória descrita não representa uma condição experimental real, em que, normalmente, a temperatura é mantida constante. Geralmente, esse tipo de amostragem é utilizado para identificar reações unimoleculares que seguem um comportamento não RRKM. Para representar condições experimentais usuais, o tipo de amostragem não deve ser aleatório; deve, geralmente, representar uma temperatura específica (conjunto canônico). Além disso, mesmo 
que os núcleos se movam classicamente, pode ser também necessário que os estados clássicos sejam amostrados como seus análogos em mecânica quântica, sendo, portanto, necessário adicionar a energia vibracional de ponto zero (ZPE, do inglês Zero-Point Energy). Para as simulações de dinâmica que utilizam esse tipo de amostragem, o termo quase clássico (do inglês quasiclassical) é utilizado.

A energia de uma molécula poliatômica em um estado rotovibracional específico pode ser aproximada pelos modelos de oscilador harmônico e rotor rígido simétrico,

$$
E=\sum_{\alpha=1}^{3 N-6} E_{\alpha}+E_{r}=\sum_{\alpha=1}^{3 N-6}\left(n_{\alpha}+\frac{1}{2}\right) h v_{\alpha}+E_{r}(J, K)
$$

em que $n_{\alpha}$ e $v_{\alpha}$ são o número quântico e a frequência vibracional do modo normal $\alpha$, respectivamente, e $E_{r}$ é a energia rotacional do rotor simétrico apresentada na Equação 1.20.

Nas simulações de dinâmica com trajetórias quase clássicas, as energias rotacionais e vibracionais para um dado reagente são escolhidas a partir de uma distribuição de Boltzmann na temperatura T. Assim, as energias dos modos normais podem ser amostradas usando uma distribuição de probabilidade, como, por exemplo,

$$
P\left(n_{\alpha}\right)=\mathbb{Q}_{\alpha}^{-1}(T) e^{-\frac{\left(\mathrm{n}_{\alpha}+\frac{1}{2}\right) h v_{\alpha}}{k_{\mathrm{B}} T}}
$$

em que $n_{\alpha}$ e $v_{\alpha}$ continuam sendo o número quântico e a frequência do $\alpha$-ésimo modo normal; $\mathbb{Q}_{\alpha}(T)$ é a função de partição vibracional do modo normal $\alpha$; e $k_{\mathrm{B}}$ é a constante de Boltzmann. Uma amostragem análoga é realizada para os números quânticos rotacionais, utilizando um rotor rígido simétrico caracterizado pelas componentes $I_{x}$ e $I_{z}$ do momento de inércia. Nesse caso, as componentes do momento angular $j$ da molécula e sua projeção $j_{z}$ são amostradas a partir de suas distribuições de Boltzmann clássicas, usando distribuições de probabilidade, como, por exemplo:

$$
\begin{array}{ll}
P\left(j_{z}\right)=e^{\left(-\frac{j_{z}^{2}}{2 I_{z} k_{\mathrm{B}} T}\right)} & 0 \leq j_{z} \leq \infty \\
P(j)=j e^{\left(-\frac{j^{2}}{2 I_{z} k_{\mathrm{B}} T}\right)} & j_{z} \leq j \leq \infty
\end{array}
$$

As relações dos números quânticos rotacionais $J$ e $K \operatorname{com} j$ e $j_{z}$ são expressas por:

$$
j=\sqrt{J(J+1) \hbar} \text { e } j_{z}=K \hbar .
$$




\subsubsection{Reações bimoleculares}

O tipo de amostragem utilizado nas reações bimoleculares é fundamentado na teoria das colisões. ${ }^{45}$ Nessa teoria, a seção de choque (transversal) de reação, entre os reagentes A e B, para formar o produto $\mathrm{P}$, pode ser determinada em função das velocidades relativas, $v_{r e l}$ e dos estados rotovibracionais de A e B. Para reações em equilíbrio térmico, as seções de choque reacionais devem ser ponderadas pela distribuição de Boltzmann para fornecer a constante de velocidade $k(T)$ da reação.

Para moléculas poliatômicas A e B, a seção de choque reativa pode ser expressa como $\sigma_{r}=\sigma_{r}\left(\mathrm{v}_{r e l}, n_{\mathrm{A}}, J_{\mathrm{A}}, K_{\mathrm{A}}, n_{\mathrm{B}}, J_{\mathrm{B}}, K_{\mathrm{B}}\right)$, em que $n_{\mathrm{A}(\mathrm{B})}, J_{\mathrm{A}(\mathrm{B})}$ e $K_{\mathrm{A}(\mathrm{B})}$ são os números quânticos vibracional e rotacionais, respectivamente, da molécula $A(B)$. Admitindo equilíbrio térmico entre os reagentes em uma temperatura $T$, a seção de choque reacional torna-se:

$\sigma_{r}\left(v_{r e l} ; T\right)=\sum_{n_{\mathrm{A}}, n_{\mathrm{B}}} \sum_{\substack{\mathrm{A}_{\mathrm{A}}, \mathrm{B}_{\mathrm{B}} \\ \mathrm{K}_{\mathrm{A}}, K_{\mathrm{B}}}} \sigma_{r}\left(v_{r e l}, n_{\mathrm{A}}, J_{\mathrm{A}}, K_{\mathrm{A}}, n_{\mathrm{B}}, J_{\mathrm{B}}, K_{\mathrm{B}}\right) P\left(n_{\mathrm{A}}, n_{\mathrm{B}}, T\right) P\left(J_{\mathrm{A}}, J_{\mathrm{B}}, K_{\mathrm{A}}, K_{\mathrm{B}}, T\right)$

em que $P\left(n_{\mathrm{A}}, n_{\mathrm{B}}, T\right)$ e $P\left(J_{\mathrm{A}}, J_{\mathrm{B}}, K_{\mathrm{A}}, K_{\mathrm{B}}, T\right)$ são as distribuições de Boltzmann normalizadas para os graus de liberdade vibracionais, $n_{\mathrm{A}(\mathrm{B})}$, e rotacionais, $J_{\mathrm{A}(\mathrm{B})}$ e $K_{\mathrm{A}(\mathrm{B})}$, na temperatura T. A multiplicação da Equação 1.28 por $v_{\text {rel }}$ resultará na constante de velocidade para uma velocidade relativa fixa:

$$
k\left(v_{r e l} ; T\right)=v_{r e l} \sigma_{r}\left(v_{r e l} ; T\right)
$$

Integrando a constante de velocidade sobre todas as velocidades ponderadas pela distribuição de Boltzmann, tem-se a constante de velocidade de uma reação térmica bimolecular.

$$
k(T)=\int_{0}^{\infty} v_{r e l} \sigma_{r}\left(v_{r e l} ; T\right) P\left(v_{r e l} ; T\right) \mathrm{d} v_{r e l}
$$

A expressão clássica da seção de choque de reação é expressa por:

$$
\sigma_{r}=\int_{0}^{b_{\max }} P_{r}(b) 2 \pi b \mathrm{~d} b
$$

em que $b$ é o parâmetro de impacto; $b_{\text {máx }}$ é o maior valor do parâmetro de impacto que produz a reação; e $P_{r}(b)$ é a probabilidade de reação em uma função do parâme-

45 Henriksen e Hansen (2008). 
tro de impacto. Para valores de $b$ escolhidos aleatoriamente entre 0 e $b_{\text {máx }}$, a média da probabilidade de reação é $N_{r} / N$, em que $N$ é o número total de trajetórias e $N_{r}$ são as trajetórias reativas. Desse modo, a seção de choque de reação é:

$$
\sigma_{r}=\frac{N_{r}}{N} \pi b_{\text {máx }}^{2}
$$

Logo, a amostragem em reações bimoleculares é realizada variando-se o parâmetro de impacto $(b)$, as orientações relativas $\left(\Omega_{\mathrm{A}}, \Omega_{\mathrm{B}}\right)$ e a velocidade $\left(v_{\text {rel }}\right)$ ou a correspondente energia de colisão $\left(E_{c o l}\right)$. Se a amostragem é realizada de forma adequada, pode-se determinar a seção de choque de reação e, por consequência, a constante de velocidade. Além disso, para cada conjunto de $b,\left(\Omega_{\mathrm{A}}, \Omega_{\mathrm{B}}\right)$ e $v_{\text {rel }}$ ou $E_{c o l}$, amostragens nas condições iniciais dos números quânticos $n_{\mathrm{A}(\mathrm{B})}, J_{\mathrm{A}(\mathrm{B})}$ e $K_{\mathrm{A}(\mathrm{B})}$ devem ser feitas de modo similar às realizadas nas simulações de reações unimoleculares.

\subsubsection{Amostragem a partir do estado de transição (TS)}

Simulações de dinâmica direta com métodos de estrutura eletrônica acurados podem ser realizadas para se estudar eventos químicos determinados por efeitos que ocorrem após o estado de transição (pós-TS). De fato, tais eventos são limitações inerentes, por exemplo, à teoria do estado de transição, pois não considera os efeitos da PES após o TS. Em particular, bifurcações na PES, após o TS, são determinantes na proporção de produtos, isto é, determinam a seletividade da reação. ${ }^{46}$ Apesar da alta demanda computacional, em razão do uso de métodos acurados de estrutura eletrônica em cada passo de integração da trajetória, o número de passos é relativamente pequeno, pois a trajetória se inicia na estrutura do TS.

Uma questão interessante que surge nesse tipo de procedimento da dinâmica a partir do TS está associada ao tipo de amostragem a ser utilizado. Os avanços da espectroscopia de femtossegundos têm tornado possível excitar e selecionar estados específicos do complexo ativado de certos sistemas reacionais, ${ }^{47}$ e, portanto, a escolha das condições iniciais da dinâmica consistentes com as populações desses estados permite simular as condições experimentais. No entanto, esses experimentos são muito difíceis de serem realizados e, em geral, considera-se que as populações dos estados rotacionais e vibracionais do TS podem ser amostradas utilizando teorias estatísticas.

A teoria do estado de transição (TST) convencional considera que existe uma distribuição de equilíbrio dos estados do TS e dos reagentes. A constante de velocidade TST é expressa por:

46 Rehbein e Carpenter (2011).

47 Polanyi e Zewail (1995). 


$$
k(T)=\frac{k_{\mathrm{B}} T}{h} \frac{\mathbb{Q}^{\ddagger}}{\mathbb{Q}_{r}} e^{-\frac{E_{a}}{k_{\mathrm{B}} T}}
$$

em que $\mathbb{Q}^{\ddagger}$ e $\mathbb{Q}_{r}$ são a função de partição molecular do TS e dos reagentes, respectivamente, e $E_{a}$ é a energia crítica ou, aproximadamente, a energia de ativação. O modelo semiclássico rotor-rígido/modo-normal pode ser utilizado para amostrar os estados do TS. Logo, as amostragens nas condições iniciais dos números quânticos $n$ (vibracional), J e $K$ (rotacionais) são realizadas de modo similar àquelas apresentadas para as reações unimoleculares. Nessa aproximação, a coordenada de reação, associada à frequência imaginária do TS, é tratada como uma coordenada translacional com energia $E_{t}^{\ddagger}$, sendo amostrada de maneira clássica. Os valores de $E_{t}^{\ddagger}$ são selecionados de acordo com a seguinte função de distribuição:

$$
P\left(E_{t}^{\ddagger}\right)=\frac{1}{k_{\mathrm{B}} T} e^{-\frac{E_{t}^{\ddagger}}{k_{\mathrm{B}} T}}
$$

os quais podem ser amostrados por uma função de distribuição cumulativa:

$$
E_{t}^{\ddagger}=-k_{\mathrm{B}} T \ln (1-R)
$$

em que $R$ é um número aleatório. $\mathrm{O}$ momento da coordenada de reação é expresso por $P_{t}^{\ddagger}=2\left(E_{t}^{\ddagger}\right)^{1 / 2}$.

$\mathrm{Na}$ formulação microcanônica, por exemplo, com base na teoria RRKM, considera-se que todos os estados rotacionais e vibracionais dos graus de liberdade ortogonais à coordenada de reação têm igual probabilidade de serem populados. Ao considerar um rotor rígido simétrico, a energia do TS é escrita como:

$$
E^{\ddagger}=E_{n J K}^{\ddagger}+E_{t}^{\ddagger}
$$

em que $E^{\ddagger}$ é a altura da barreira; $E_{t}^{\ddagger}$ é a energia da coordenada translacional; e $E_{n J K}^{\ddagger}$ é a energia dos níveis rotacionais e vibracionais dos graus de liberdade ortogonais à coordenada de reação. $O$ primeiro passo é selecionar aleatoriamente a energia do TS, $E^{\ddagger}$, sendo a energia restante, $E^{\ddagger}-E_{n J K}^{\ddagger}$, alocada na coordenada translacional, $E_{t}^{\ddagger}$.

Uma aplicação interessante desse tipo de simulação a partir do TS está na possibilidade de corrigir o valor da constante de velocidade obtida pelas teorias estatísticas, ${ }^{48}$ isso porque a TST canônica ou microcanônica fundamenta-se na suposição de as trajetórias cruzarem a superfície do TS apenas uma vez. Portanto, os recruzamentos de barreira não são considerados pela TST. O procedimento realizado para corrigir a constante de velocidade consiste em determinar o número 
de recruzamentos de barreira, que podem ser contabilizados iniciando trajetórias a partir do TS com amostragens dos graus de liberdade a partir de uma distribuição de Boltzmann apropriada.

\subsubsection{Crítica à literatura: dinâmica ab initio}

A utilização do termo ab initio para descrever métodos dinâmicos precisa ser considerada de modo mais aprofundado ${ }^{49}$ Em estrutura eletrônica, assume-se que um método é $a b$ initio quando não utiliza dado ou parâmetro experimental, exceto pelas constantes fundamentais, e que, por algum procedimento hierárquico (bem definido e único), possa levar à solução exata da equação de Schrödinger eletrônica, independentemente do tempo. Assumindo os mesmos critérios para métodos dinâmicos, estes, para serem ab initio, teriam que fornecer a solução exata da equação de Schrödinger, dependente do tempo para elétrons e núcleos. Logo, a simples utilização de métodos $a b$ initio para calcular a energia eletrônica e suas derivadas em uma dada configuração nuclear não fornece um método de dinâmica $a b$ initio, pois não há um procedimento para seu aprimoramento que leve à solução exata da equação de Schrödinger, dependente do tempo. Mesmo que os graus de liberdade eletrônicos sejam tratados dinamicamente, por uma lagrangiana extendida, por exemplo, não caracteriza um método de dinâmica $a b$ initio, pois o requisito apresentado anteriormente não é satisfeito. De fato, existe um formalismo denominado dinâmica de elétrons e núcleos (END, do inglês Electron-Nuclear Dynamics), que é $a b$ initio, pois satisfaz os critérios citados. Foram propostos doze níveis de aproximações hierárquicas que fornecem um procedimento único para a solução exata. ${ }^{50}$ O nível mais simples consiste em descrever a função de onda eletrônica por um determinante e a função de onda nuclear por funções gaussianas com larguras nulas (núcleos clássicos). Note, entretanto, que, mesmo nessa aproximação mais simples, os movimentos eletrônicos e nucleares são acoplados.

Com essas observações, tem-se que os métodos de dinâmica molecular, isto é, aqueles que tratam os graus de liberdade nuclear classicamente, não podem ser considerados $a b$ initio, pois não fornecem a solução exata da equação de Schrödinger, dependente do tempo. Assim, os métodos de "dinâmica molecular ab initio" apresentados na literatura são, de fato, métodos de dinâmica clássica nuclear que utilizam cálculos ab initio (nem sempre no sentido aqui empregado para esses métodos de estrutura eletrônica) da energia eletrônica e suas derivadas. O termo ab initio, contudo, praticamente se tornou sinônimo de método preciso ou acurado ou de referência, e muitos autores o utilizam, por vezes inadequadamente, para designar métodos de dinâmica molecular que utilizam potenciais quânticos, em contraste com métodos de dinâmica molecular que utilizam potenciais clássicos com base em campos de força.

49 Marx e Hutter (2009), Car et al. (2005).

50 Öhrn e Deumens (1999). 


\subsubsection{Comparações com a dinâmica quântica: limitações da BOMD}

Por se basear na aproximação de Born-Oppenheimer, esse tipo de dinâmica direta não pode ser utilizada, sem modificações, para descrever regiões da PES próximas às interseções cônicas, ou melhor, nas reações em que os termos de acoplamento elétron-núcleo não podem ser desprezados.

Outra limitação desse método, e dos métodos de dinâmica molecular em geral, está na utilização de trajetórias clássicas para simular sistemas quânticos. Nesse caso, alguns efeitos intrínsecos da mecânica quântica não são considerados, como tunelamento, interferências e trocas de energia quantizada entre os graus de liberdade. Além disso, não existe um análogo clássico para a ZPE. Assim, em uma trajetória clássica, um modo normal pode ter energia menor que sua respectiva $\mathrm{ZPE}$, sendo uma situação impossível quanticamente..$^{51}$

Comparações realizadas na literatura têm mostrado que os resultados obtidos de dinâmicas quase clássicas com tempo curto de simulação estão frequentemente de acordo com os observados nas simulações de dinâmica quântica e com os resultados experimentais. Entretanto, quando as trajetórias quase clássicas são conduzidas por longos tempos de propagação, podem-se notar, em alguns casos, divergências acentuadas com os resultados obtidos por dinâmica quântica, ${ }^{52}$ sendo a troca de energia não quantizada entre os graus de liberdade a causa principal para essas divergências.

\subsubsection{Programas para simulações BOMD}

Nesses últimos vinte anos, é inegável que a popularidade do método BOMD para o estudo de reações químicas vem associada à implementação dos códigos de dinâmica direta em programas populares de cálculos de estrutura eletrônica, como GAMESS, Gaussian, DALTON, ORCA, NWChem, MOPAC, entre outros.

Os programas Gaussian, GAMESS, DALTON e ORCA apresentam rotinas específicas para cálculos de dinâmica molecular direta, enquanto os programas NWChem e MOPAC apresentam interface com o código VENUS..$^{53}$ O VENUS é, sem dúvida, o programa mais completo de dinâmica direta. Nele existe um conjunto amplo de opções, entre as quais estão:

i. Rotinas apropriadas para realizar amostragens iniciais - sejam clássicas, sejam quase clássicas (canônicas ou microcanônicas), além da possibilidade de incluir as contribuições translacionais, rotacionais e vibracio-

51 Stock e Müller (1999).

52 Peslherbe, Wang e Hase (1995), Wyatt, Iung e Leforestier (1992), Sibert, Reinhardt e Hynes (1984), Hase e Buckowski (1982).

53 Hase et al. (1996). 
nais - dos sistemas moleculares, específicas para os diferentes tipos de reações unimoleculares, bimoleculares, a partir do TS etc.;

ii. Diferentes tipos de algoritmos para integrar as equações de movimento nuclear, com base ou não na hessiana;

iii. Rotinas para analisar propriedades moleculares - distâncias e ângulos entre átomos, cargas atômicas, entre outros tipos de análises - ao longo das trajetórias;

iv. Procedimentos que transformam os valores de momento e posição, associados às condições finais de cada trajetória, em propriedades que possam ser comparadas com os dados experimentais;

v. Interface com programas gráficos para visualização dos movimentos dos átomos durante a dinâmica da reação.

Os programas Gaussian e GAMESS apresentam, em contraste, um conjunto menor de opções para esse tipo de dinâmica direta, se comparados, por exemplo, com a interface NWChem/VENUS. Portanto, para possíveis utilizações dos módulos de dinâmica direta dos programas Gaussian e GAMESS, tornam-se indispensáveis as construções de rotinas para realizar as amostragens iniciais dos sistemas moleculares adequadas ao tipo de reação unimolecular, ${ }^{54}$ bimolecular, entre outras, bem como para analisar as propriedades moleculares ao longo das trajetórias e das condições finais.

\subsection{EXPLORANDO MECANISMOS E SELETIVIDADES DE REAÇõES QUíMICAS}

Entender os aspectos que controlam a seletividade química é fundamental tanto para esclarecer como os mecanismos de reação ocorrem quanto para modificar as condições reacionais a fim de obter o produto desejado. Comumente, a seletividade química pode ser entendida considerando dois fatores: a variação da energia livre do sistema (que atua no controle termodinâmico da reação) e a velocidade de conversão de reagentes em produtos (relacionada ao controle cinético). ${ }^{55}$ Quando as reações estão sob controle termodinâmico, a seletividade é completamente estabelecida pela relação da energia livre de Gibbs entre os produtos, sendo os mecanismos de reação irrelevantes na razão dos produtos. Entretanto, quando as reações são conduzidas em condições em que aos produtos não é permitido estarem em equilíbrio ou em condições em que o controle termodinâmico não pode ser estabelecido, ${ }^{56}$ os mecanismos de reações desempenham papel essencial no controle da seletividade, sendo que para essas situações diz-se que o controle cinético da seletividade se estabelece.

\footnotetext{
54 É bem verdade que no programa Gaussian existe um bom conjunto de opções apenas para reações unimoleculares, similar ao programa VENUS.

55 Anslyn e Dougherty (2006).

56 Riveros, Maria José e Takashima (1985).
} 
Convencionalmente, na química moderna, o controle cinético da seletividade, por muito tempo, foi apenas associado à barreira de energia na superfície de energia potencial que os reagentes têm que ultrapassar para atingir os produtos. Geralmente, a compreensão do controle cinético da seletividade passa pelo entendimento de como a energia livre de Gibbs da "espécie" estado de transição responde às mudanças das condições reacionais (solvente, temperatura, substituintes etc.). Nesse sentido, a química teórica/computacional tem sido uma ferramenta importante no entendimento e na antecipação da seletividade química. $\mathrm{Na}$ construção do entendimento do controle cinético da seletividade ao longo da história da química moderna, a metodologia computacional dita estática tem fornecido um bom arcabouço conceitual para o entendimento de muitas reações químicas. ${ }^{57} \mathrm{~A}$ metodologia estática é composta de dois tratamentos que se complementam, a saber: (i) varredura da superfície de energia potencial (PES), determinando e caracterizando pontos críticos na PES - os reagentes, produtos, intermediários e TS são analisados em função de suas propriedades estruturais e energéticas; e (ii) as teorias estatísticas do estado de transição (TST) e RRKM, que permitem interpretar de forma qualitativa e (semi)quantitativa as velocidades e seletividades de reações químicas.

É inegável o sucesso do tratamento estático no estudo de reações químicas. Entretanto, nos últimos anos, tornou-se evidente que, para muitas reações químicas, o controle cinético da seletividade não pode ser reduzido simplesmente a uma comparação das alturas de barreiras dos diferentes canais reacionais, particularmente com os estudos de dinâmica de reações computacionais e experimentais. ${ }^{58}$

Os estudos de dinâmica das reações químicas têm sugerido que, além do controle cinético convencional da seletividade, ou seja, com base apenas nas alturas das barreiras de energia, o controle cinético da seletividade pode também ser estabelecido por variáveis intrinsecamente dinâmicas ou por comportamentos que só podem ser descritos pela dinâmica, quais sejam: (i) mecanismos e seletividades de reações dirigidas pelo momento; ${ }^{59}$ (ii) seletividades em bifurcações na PES pós-TS; ${ }^{60}$ e (iii) reações que evitam o caminho de energia mínima na $\mathrm{PES}^{61}$ e com o comportamento da seletividade fora das condições estatísticas. ${ }^{62}$

Aplicações da metodologia BOMD, em duas reações químicas, com foco no entendimento mais completo dos mecanismos e seletividades reacionais, serão apresentadas nas próximas seções. Mais detalhes sobre esses estudos podem ser encontrados em De Souza e De Souza et al. ${ }^{63}$ Todas as simulações e os cálculos de estrutura eletrônica que serão apresentados foram realizados com o programa Gaussian 09.

57 Bachrach (2007).

58 Manikandan, Zhang e Hase (2012), Mikosch et al. (2008), López et al. (2007), Carpenter (2003, 2005), Chabinyc et al. (1998).

59 Mikosch et al. (2008).

60 Rehbein e Carpenter (2011).

61 Ammal et al. (2003), Sun, Song e Hase (2002).

62 De Souza et al. (2012), Quijano e Singleton (2011).

63 De Souza (2012), De Souza et al. (2012). 


\subsubsection{Reação de desidratação do álcool pinacolílico protonado: mecanismo dirigido pela dinâmica}

Nos estudos cinéticos, muito tem sido feito para compreender como distinguir um mecanismo concertado daquele em etapas. Esse é aparentemente um problema bem definido - mecanismos concertados ocorrem por uma via, envolvendo um único TS, enquanto um mecanismo em etapas passa necessariamente por pelo menos dois TS, com um intermediário interveniente. No entanto, um trabalho importante de simulações $\mathrm{BOMD}^{64}$ mostrou que, em reações que evitam o caminho de energia mínima na PES, a distinção entre o mecanismo em etapas e o concertado utilizando critérios estáticos, isto é, números de estados de transição, não fornece resultados adequados.

A reação estudada está relacionada com a desidratação do álcool protonado 3,3-dimetilbutan-2-ol (álcool pinacolílico), $\left[\mathrm{Me}_{2}(\mathrm{Me}) \mathrm{C}-\mathrm{CH}\left(\mathrm{OH}_{2}\right) \mathrm{Me}\right]^{+}, \mathrm{Me}$, seguido de um rearranjo para a formação do carbocátion mais estável (terciário). Dois mecanismos reacionais limites são propostos para essa reação, a saber: (i) concertado - sendo representado por um único TS -, em que a saída da molécula de água e a migração do grupo metila ocorrem de forma concertada; e (ii) em etapas - sendo representativa para esse caminho há a formação do intermediário reacional -, inicialmente sai a molécula de água e a formação de um carbocátion secundário; em seguida, em um passo distinto, ocorre a migração da metila. Esses dois mecanismos estão ilustrados esquematicamente na Figura 1.2.

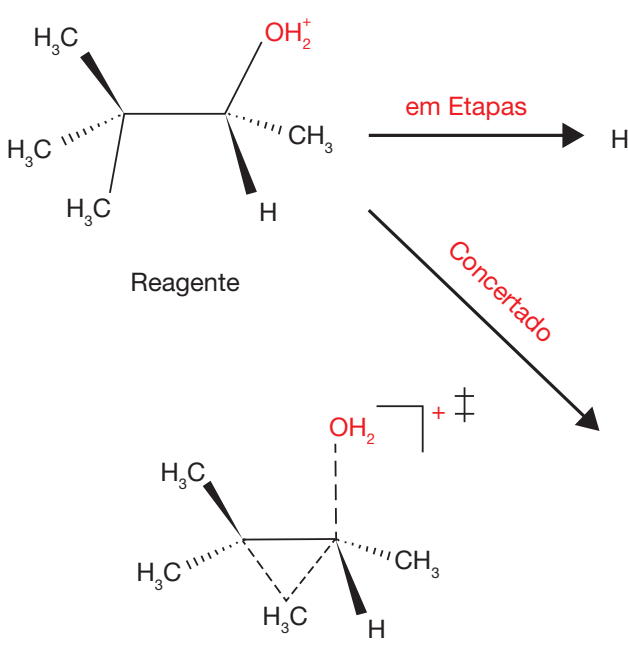

TS

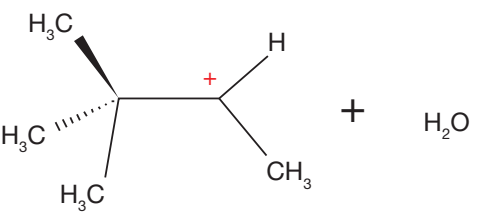

Intermediário

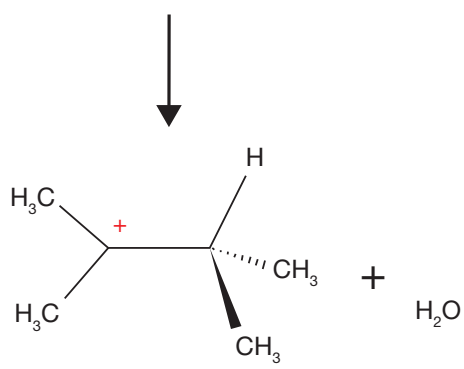

Produto

Figura 1.2 Representação esquemática de dois mecanismos de reações limites do álcool pinacolílico protonado, a saber: em etapas e concertado.

64 Ammal et al. (2003). 
Os cálculos de estrutura eletrônica (varredura na PES, determinação dos pontos estacionários e cálculo IRC) sugerem um mecanismo concertado referente ao caminho de energia mínima na PES. No entanto, as simulações BOMD mostram que a maioria das trajetórias segue um caminho em etapas, sendo inicialmente formado o carbocátion secundário. Assim, em efeito, o mecanismo de reação é dirigido pelos aspectos dinâmicos.

A seguir serão confrontadas as duas interpretações oriundas das metodologias estática (determinação de pontos críticos e cálculos IRC) e dinâmica (simulações BOMD) do mecanismo de reação de desidratação do álcool pinacolílico protonado.

\subsubsection{Resultados da superfície de energia potencial}

Na Figura 1.3 está mostrado o contorno tridimensional da PES para a desidratação do álcool pinacolílico protonado, bem como as estruturas dos principais pontos estacionários. Nessa superfície de contorno estão projetadas curvas pontilhadas (em cor branca) relacionadas ao comportamento de $\mathrm{R}_{\mathrm{C} 2-\mathrm{O}}$ versus $\theta_{\mathrm{C} 2-\mathrm{C} 3-\mathrm{C} 4}$ ao longo da IRC. Nesta figura, as cores servem de base para diferenciar as três regiões mais relevantes da PES, a saber: em azul estão o reagente $\left(\mathrm{R}_{\mathrm{C} 2-\mathrm{O}} \approx 1,6 \AA\right.$ e $\theta_{\mathrm{C} 2-\mathrm{C} 3-\mathrm{C} 4} \approx$ $\left.105^{\circ}\right)$ e o complexo dos produtos $\left(\mathrm{R}_{\mathrm{C} 2-\mathrm{O}} \approx 3,5 \AA\right.$ e $\left.\theta_{\mathrm{C} 2-\mathrm{C} 3-\mathrm{C} 4} \approx 40^{\circ}\right)$; em verde está o TS $\left(\mathrm{R}_{\mathrm{C} 2-\mathrm{O}} \approx 2,8 \AA\right.$ e $\left.\theta_{\mathrm{C} 2-\mathrm{C} 3-\mathrm{C} 4} \approx 73^{\circ}\right)$ e o intermediário $\left(\mathrm{R}_{\mathrm{C} 2-\mathrm{O}} \approx 3,8 \AA\right.$ e $\left.\theta_{\mathrm{C} 2-\mathrm{C} 3-\mathrm{C} 4} \approx 98^{\circ}\right)$; e em vermelho e laranja as regiões de maior energia da PES, associadas a uma estrutura em que o carbono ligado à molécula da água está rodeado por cinco grupos.

O caminho de energia mínima obtido na reação se caracteriza por um mecanismo concertado, em que a saída da molécula da água é concomitante com a migração do grupo alquila. Um caminho de reação alternativo em etapas, relacionado ao canal de eliminação-rearranjo, foi também exaustivamente estudado. No entanto, nenhum mínimo local associado ao carbocátion secundário foi localizado nos três sistemas reacionais: $\left[\mathrm{Me}_{2}(\mathrm{Me}) \mathrm{C}-\mathrm{CH}\left(\mathrm{OH}_{2}\right) \mathrm{Me}\right]^{+}, \mathbf{M e},\left[\mathrm{Me}_{2}(\mathrm{Et}) \mathrm{C}-\mathrm{CH}\left(\mathrm{OH}_{2}\right) \mathrm{Me}\right]^{+}, \mathbf{E t}$, e $\left[\mathrm{Me}_{2}(\mathrm{i}-\mathrm{Pr}) \mathrm{C}-\mathrm{CH}\left(\mathrm{OH}_{2}\right) \mathrm{Me}\right]^{+}$, i-Pr, em que somente o primeiro sistema será analisado. Várias tentativas foram realizadas com a geometria inicial dos sistemas na região I da PES (Figura 1.3), porém, em todos os casos, os processos de minimização das estruturas levaram aos reagentes.

\subsubsection{Resultados das simulações de BOMD}

As trajetórias de BOMD foram iniciadas na estrutura do reagente. Ao todo, foram realizadas 100 trajetórias em que se computaram as energias, os gradientes e as hessianas (com a opção "update $=5$ ", isto é, a hessiana é recalculada a cada cinco passos de integração), com o método B3LYP/6-31+G(d). O procedimento de inicialização das trajetórias consistiu em distribuir aleatoriamente, para todos os modos 
normais, dois diferentes valores de energia: 20,0 e 35,0 kcal mol${ }^{-1}$. A amostragem quase clássica, a qual incluiu a ZPE, foi usada para selecionar as condições iniciais dos momentos, sendo considerados apenas os graus de liberdade vibracionais (não foram incluídas as energias rotacional e translacional). As trajetórias simuladas foram propagadas por um tempo entre 0,5 e 1,5 ps.

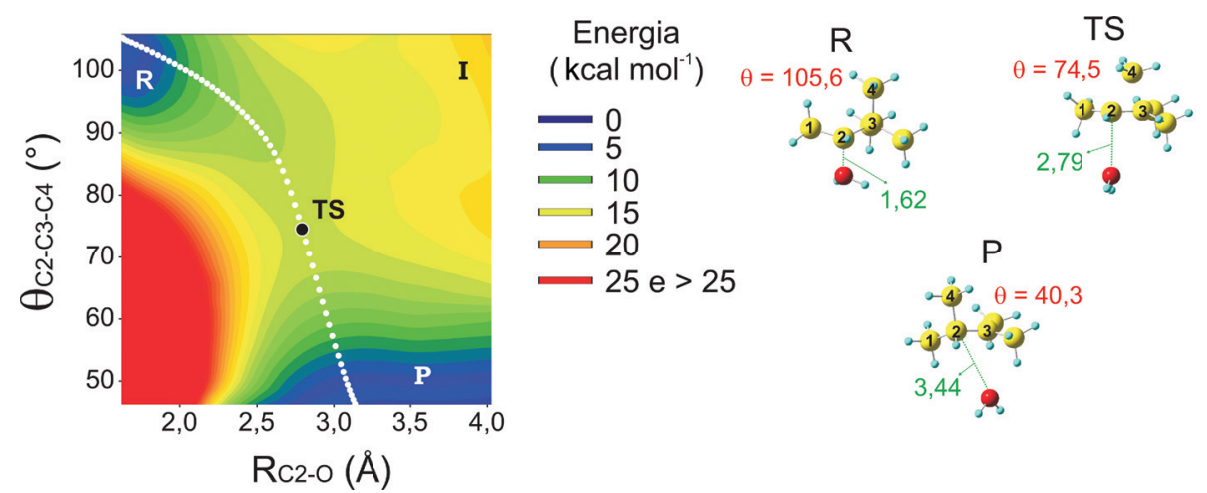

Figura 1.3 $\mathrm{R}_{\mathrm{C} 2-\mathrm{O}}$ e $\theta_{\mathrm{C} 2-\mathrm{C} 3 \mathrm{C} 4}$ em termos de contornos da PES, obtidos para a reação de desidratação do álcool pinacolílico protonado, seguido de rearranjo para o carbocátion mais estável. A PES foi calculada pelo procedimento de varredura relaxada, sendo as minimizações restritas realizadas para as coordenadas $\mathrm{R}_{\mathrm{C} 2-\mathrm{O}}$ e $\theta_{\mathrm{C} 2-\mathrm{C} 3-\mathrm{C} 4}$. Todos os cálculos foram realizados com o método B3LYP/6-31G(d). As regiões mais relevantes das PES estão denominadas por R, P, TS e I. As estruturas dos pontos estacionários principais estão ilustradas da seguinte forma: reagente $(\mathrm{R})$, estado de transição (TS) e produto $(\mathrm{P})$.

Inicialmente, as trajetórias foram propagadas até 0,5 ps. Nesse período, um número muito pequeno de trajetórias reativas foi obtido: $18 \%$ e $36 \%$, para $E_{i n i}=$ 20,0 e $35,0 \mathrm{kcal} \mathrm{mol}^{-1}$, respectivamente. Esse percentual de trajetórias reativas não é satisfatório, já que a eficiência de reação é pequena, o que poderia não suportar uma estatística significativa para a predição do mecanismo reacional. Portanto, as trajetórias foram propagadas por mais tempo, aproximadamente 1,0 ps. Com esse maior tempo de simulação, um número considerável de trajetórias deixou a região dos reagentes, sendo $62 \%$ e $78 \%$ para as duas energias $E_{i n i}=20,0$ e $35,0 \mathrm{kcal} \mathrm{mol}^{-1}$, respectivamente. Para algumas trajetórias foi necessário propagar por mais tempo, sendo que o tempo máximo de propagação foi de 1,5 ps. 

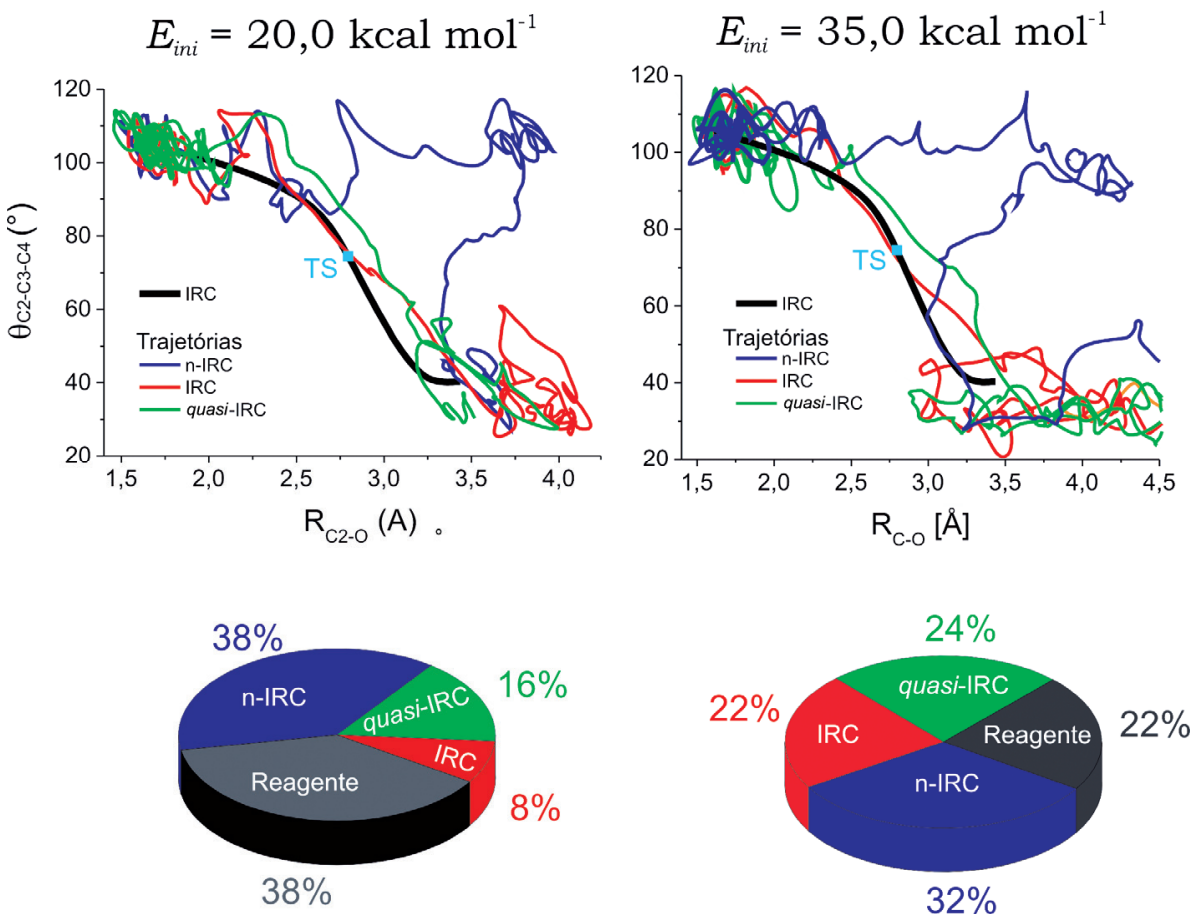

Figura 1.4 Comportamento de trajetórias reativas típicas observadas nas simulações da reação $\left[\mathrm{Me}_{2}(\mathrm{Me}) \mathrm{C}-\mathrm{CH}\left(\mathrm{OH}_{2}\right) \mathrm{Me}\right]^{+}$, tendo como condição inicial da dinâmica as energias $E_{i n i}=20,0$ e 35,0 $\mathrm{kcal} \mathrm{mol}^{-1}$, distribuídas aleatoriamente, juntamente com a ZPE, nos modos normais (quase clássica). Na parte superior são mostradas as variações de $\theta_{\mathrm{C} 2-\mathrm{C} 3-\mathrm{C} 4}\left({ }^{\circ}\right)$ versus $\mathrm{R}_{\mathrm{C} 2-\mathrm{O}}(\AA)$, para os três tipos de trajetórias reativas observadas: IRC, n-IRC e quasi-IRC, representadas pelas linhas nas cores vermelho, azul e verde, respectivamente. Além disso, neste gráfico é mostrado também o comportamento de $\theta_{\mathrm{C} 2-\mathrm{C} 3-\mathrm{C} 4}$ versus $\mathrm{R}_{\mathrm{C} 2-\mathrm{O}}$ do caminho de energia mínima (IRC) na PES (linha mais cheia em cor preta) e o valor de $\theta_{\mathrm{C} 2-\mathrm{C} 3-\mathrm{C} 4}$ versus $\mathrm{R}_{\mathrm{C} 2-\mathrm{O}}$ do TS (ponto em cor azul). Já na parte inferior desta figura, os gráficos mostram as porcentagens em função dos tipos de trajetórias obtidas nas simulações para as duas energias $E_{i n i}$.

A Figura 1.4 apresenta três tipos de trajetórias reativas observadas nas simulações, as quais foram classificadas de acordo com a proximidade ao comportamento IRC no tratamento estático, a saber:

i. Trajetória IRC - com comportamento similar ao da IRC, no método estático. Logo, nessa trajetória a reação ocorre de maneira concertada;

ii. Trajetória n-IRC - com comportamento bem diferente da IRC da PES. Nesse caso, a reação ocorre em etapas, ou seja, ocorre inicialmente a formação do carbocátion secundário; 
iii. Trajetória quasi-IRC - que apresenta um comportamento próximo ao da IRC no método estático.

Na Figura 1.4 estão apresentados também gráficos das porcentagens dos tipos de trajetórias observados nas simulações: IRC, n-IRC e quasi-IRC. De fato, para $E_{\text {ini }}$ $=20,0 \mathrm{kcal} \mathrm{mol}^{-1}$, o número de trajetórias n-IRC é bem maior do que aqueles observados nas outras trajetórias reativas. Este resultado é bastante similar ao obtido por Ammal et al. ${ }^{65}$ Entretanto, para a energia $E_{i n i}=35,0 \mathrm{kcal} \mathrm{mol}^{-1}$, o resultado é bastante surpreendente. $\mathrm{O}$ número de trajetórias IRC e quasi-IRC se torna maior, quer dizer, o aumento de energia distribuída aleatoriamente aos modos normais favoreceu o caminho concertado.

Na Figura 1.5 é mostrado o comportamento da distância $\mathrm{R}_{\mathrm{C} 2-\mathrm{O}}$ e do ângulo $\theta_{\mathrm{C2}-\mathrm{C} 3-\mathrm{C} 4}$, em função do tempo de simulação, para quatro trajetórias reativas típicas observadas, para $\left[\mathrm{Me}_{2}(\mathrm{Me}) \mathrm{C}-\mathrm{CH}\left(\mathrm{OH}_{2}\right) \mathrm{Me}\right]^{+}$, Me. Para três trajetórias reativas - IRC, quasi-IRC e n-IRC -, verifica-se que, entre 500 e 600 fs, a distância $\mathrm{R}_{\mathrm{C} 2-\mathrm{O}}$ se torna superior a 2,8 $\AA$, indicando que a ligação $\mathrm{C}-\mathrm{O}$ já está rompida. A partir desse período da dinâmica, as três trajetórias reativas têm comportamentos bem distintos, que podem ser verificados analisando a relação entre $\theta_{\mathrm{C} 2-\mathrm{C} 3-\mathrm{C} 4}$ e $\mathrm{R}_{\mathrm{C} 2-\mathrm{O}}$ no restante do percurso, a saber:

i. Na trajetória IRC, o ângulo $\theta_{\mathrm{C2}-\mathrm{C} 3 \mathrm{C} 4}$ é aproximadamente $75^{\circ}$ (é o menor valor comparado com os ângulos $\theta_{\mathrm{C} 2-\mathrm{C} 3-\mathrm{C} 4}$ das outras trajetórias), indicando que a metila já está em processo de migração, de modo que a evolução dessa trajetória para o produto $\left(\mathrm{R}_{\mathrm{C}-\mathrm{O}}>3,5 \AA\right.$ e $\theta_{\mathrm{C} 2-\mathrm{C} 3-\mathrm{C} 4}$ oscilando em torno de $30^{\circ}$ ) é quase instantânea, sendo menor que um período vibracional de uma ligação simples típica ( $30 \mathrm{fs})$;

ii. Nas trajetórias quasi-IRC e n-IRC, os ângulos $\theta$ estão em torno de $90^{\circ}$, indicando que o carbocátion secundário está formado. A diferença das duas trajetórias está justamente no tempo de formação do produto. Enquanto na trajetória quasi-IRC o produto é formado em aproximadamente $100 \mathrm{fs}$, na n-IRC a estrutura permanece na região do carbocátion secundário por um tempo aproximado de $500 \mathrm{fs}$. 

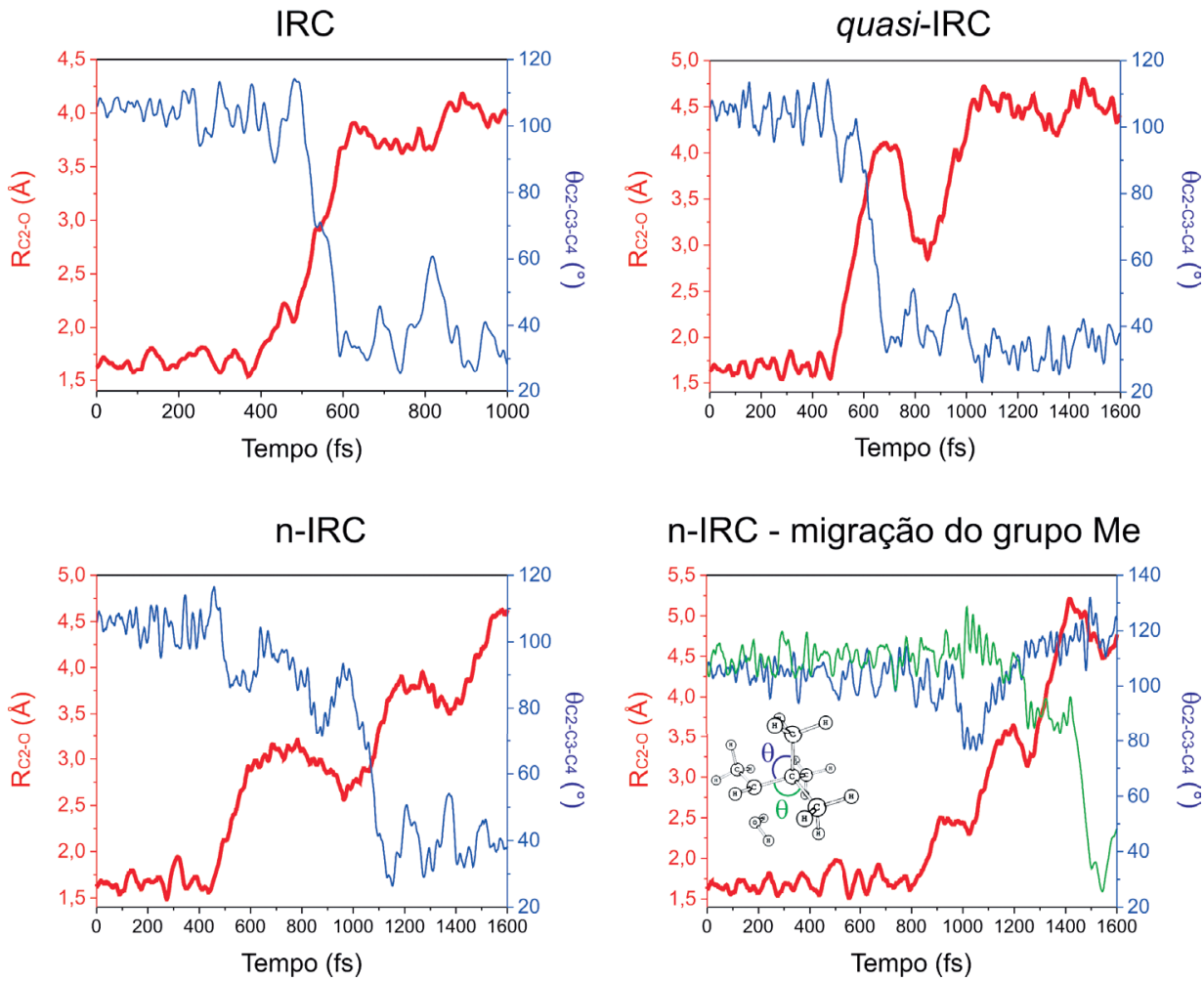

Figura 1.5 Dependência temporal de $\theta_{\mathrm{C} 2-\mathrm{C} 3-\mathrm{C} 4}\left({ }^{\circ}\right)$ e $\mathrm{R}_{\mathrm{C} 2-\mathrm{O}}(\AA)$ de quatro trajetórias reativas típicas observadas nas simulações IRC, quasi-IRC e duas n-IRC. Todas essas quatro trajetórias foram obtidas com a condição inicial de energia $E_{i n i}=20,0 \mathrm{kcal} \mathrm{mol}{ }^{-1}$, para $\left[\mathrm{Me}_{2}(\mathrm{Me})-\mathrm{C}-\mathrm{CH}-\right.$ $\left.\mathrm{Me}-\mathrm{OH}_{2}\right]^{+}, \mathrm{Me}$. Na outra trajetória n-IRC mostrada, o grupo metila migra em orientação syn ao hidrogênio (ver inserção no gráfico, $\theta_{\mathrm{C} 2-\mathrm{C} 3-\mathrm{C} 4}$, em cor verde).

Para as energias $E_{i n i}=20,0$ e $35 \mathrm{kcal} \mathrm{mol}^{-1}, 19$ e 16 trajetórias foram classificadas como n-IRC nas simulações, respectivamente. Dessas trajetórias n-IRC, 10 e 9 , respectivamente para $E_{i n i}=20,0$ e $35 \mathrm{kcal} \mathrm{mol}^{-1}$, formaram o carbocátion terciário esperado, estando associado à migração da metila em orientação anti à molécula $\mathrm{H}_{2} \mathrm{O}$. Nas três trajetórias restantes o produto esperado também foi obtido, porém ocorreu a migração das outras metilas. O comportamento de $\mathrm{R}_{\mathrm{C} 2-\mathrm{O}}$ e $\theta_{\mathrm{C} 2-\mathrm{C} 3-\mathrm{C} 4}$ de uma dessas três trajetórias é apresentado na Figura 1.5. Nessa trajetória percebe-se um comportamento típico n-IRC, mostrando que o carbocátion secundário tem um tempo de vida de aproximadamente $400 \mathrm{fs}$.

Pelo menos dois dos méritos do trabalho de Ammal et al ${ }^{66}$ estão em mostrar: (i) uma reação que tem comportamento dinâmico não IRC; e (ii) que um intermediário pode apresentar um tempo de vida muito longo, mesmo em uma região da PES 
que não apresenta um mínimo local. Segundo esse trabalho, em muitas trajetórias da reação de eliminação-rearranjo do álcool protonado, o carbocátion secundário permaneceu ativo por um período longo, por exemplo, de até $4000 \mathrm{fs}(=4,0 \mathrm{ps})$, em uma das trajetórias. Diferentemente, os resultados obtidos no estudo aqui apresentado mostram tempos de vida mais curtos para o carbocátion secundário. Para as energias $E_{i n i}=20,0$ e $35 \mathrm{kcal} \mathrm{mol}^{-1}$, foram obtidas ao todo 35 trajetórias n-IRC, sendo que o maior tempo de vida do carbocátion secundário foi de aproximadamente 530 fs. Particularmente, para 19 trajetórias n-IRC obtidas com $E_{\text {ini }}=20,0 \mathrm{kcal} \mathrm{mol}^{-1}$, em 12 delas o tempo de vida do carbocátion secundário variou entre aproximadamente 100 e $300 \mathrm{fs}$, enquanto apenas sete trajetórias tiveram tempo de vida entre 300 e 600 fs. Já para as 16 trajetórias n-IRC obtidas com $E_{i n i}=35,0 \mathrm{kcal} \mathrm{mol}^{-1}$, apenas duas trajetórias tiveram tempo de vida entre aproximadamente 300 e $600 \mathrm{fs}$; o restante ficou entre aproximadamente 100 e 300 fs.

É bastante interessante observar os efeitos que o aumento da energia cinética distribuída inicialmente aos modos normais promoveu na reação de eliminação-rearranjo do álcool protonado: (i) diminuir (em média) o tempo de vida do carbocátion secundário para as trajetórias n-IRC; e (ii) aumentar a porcentagem de trajetórias IRC e quasi-IRC.

\subsubsection{Comportamento estático versus dinâmico}

Na metodologia estática, o mecanismo de reação é concertado, ou seja, a saída da molécula de $\mathrm{H}_{2} \mathrm{O}$ é concomitante à migração do grupo metila. Diferentemente, no tratamento dinâmico, a etapa inicial da reação é o rompimento da ligação $\mathrm{C} 2-\mathrm{O}$ e a consequente saída da molécula $\mathrm{H}_{2} \mathrm{O}$. Além disso, os resultados da dinâmica mostram que o movimento inicial de migração do grupo metila não está, preferencialmente, acoplado com a saída da molécula $\mathrm{H}_{2} \mathrm{O}$.

Uma das limitações do tratamento estático, que neste estudo do mecanismo de reação do álcool pinacolílico protonado se torna relevante, é que ela se fundamenta na determinação e caracterização dos pontos críticos. Para os sistemas estudados, a determinação de um possível ponto crítico associado ao mecanismo de reação em etapas - caminho preferencial das trajetórias simuladas - não foi possível. Talvez o motivo principal para o insucesso na determinação do ponto crítico esteja na natureza da PES na região associada ao intermediário. Note que a figura - que apresenta a superfície de contorno da PES construída pelo procedimento de varredura relaxada - mostra que as diferenças de energia entre as regiões do TS e do intermediário são relativamente pequenas. Desse modo, uma possível interpretação dos resultados da dinâmica é que, em contraste com a PES, a superfície corrigida com a ZPE dê preferência ao mecanismo em etapas. Isso ocorre porque no tratamento estático, com base na IRC, os efeitos da ZPE e entrópicos não são considerados na determinação da PES. Talvez, se esses efeitos forem 
incluídos na descrição estática, os resultados sejam similares àqueles obtidos pelas simulações BOMD.

Nessa reação, a dinâmica prefere o caminho em etapas em vez do concertado, porque o movimento vibracional inicial da espécie reagente é em direção à região do cátion menos estável. Portanto, este estudo apresenta uma inovação no que se refere ao entendimento de algumas reações orgânicas, já que para a reação aqui estudada a região do TS tem importância limitada no mecanismo de reação.

\subsection{5 $\mathrm{A}$ reação $\mathrm{CH}_{3} \mathrm{ONO}_{2}+\mathrm{OH}^{-}$: seletividade dirigida pela dinâmica}

Um caso interessante, no contexto de o comportamento da seletividade estar fora das condições estatísticas, é a reação íon-molécula $\mathrm{CH}_{3} \mathrm{ONO}_{2}+\mathrm{OH}^{-},{ }^{67}$ cuja proporção dos produtos, observados experimentalmente, não é descrita adequadamente pela teoria RRKM. Essa reação foi estudada experimentalmente em condições de alto vácuo, com o espectrômetro de massa acoplado ao FT-ICR ${ }^{68}$

A cinética dessa reação é apresentada na Figura 1.6. $\mathrm{O}$ ataque nucleofílico de $\mathrm{OH}^{-}$ao nitrato de metila produziu os íons nitrito $\left(\mathrm{NO}_{2}^{-}\right)$e nitrato $\left(\mathrm{NO}_{3}^{-}\right)$, sendo que a proporção observada de $\mathrm{NO}_{2}^{-}: \mathrm{NO}_{3}^{-}$foi $0,86: 0,14$. Os produtos dessa reação podem ser racionalizados pelos mecanismos de deslocamento nucleofílico bimolecular no carbono (mecanismo $\mathrm{S}_{\mathrm{N}}$ @C), bem como uma abstração do próton seguida por dissociação (mecanismo $\mathrm{E}_{\mathrm{CO}} 2$, em que o subscrito ${ }_{\mathrm{CO}}$ está associado à eliminação da molécula de formaldeído). Entretanto, também foi considerada a possibilidade de uma substituição nucleofílica bimolecular no nitrogênio (mecanismo $\mathrm{S}_{\mathrm{N}} 2 @ \mathrm{~N}$ ), que gera o produto $\mathrm{NO}_{3}{ }^{-}$. Para investigar separadamente os mecanismos $\mathrm{S}_{\mathrm{N}} 2 @ \mathrm{C}$ e $\mathrm{S}_{\mathrm{N}} 2 @ \mathrm{~N}$, foram realizados estudos experimentais com o nucleófilo marcado isotopicamente ${ }^{18} \mathrm{OH}^{-}$. Porém, dentro do limite de detecção (valores menores que 4\%), não foi observada a incorporação do ${ }^{18} \mathrm{O}$ no produto $\mathrm{NO}_{3}{ }^{-}$. Ou seja, não há formação do íon ${ }^{18} \mathrm{ONO}_{2}^{-}\left(\mathrm{m} / z\right.$ 64) em nenhuma das reações, sugerindo que a reação $\mathrm{S}_{\mathrm{N}} 2$ ocorre exclusivamente no carbono. Os caminhos reacionais possíveis estão ilustrados no Esquema 1.1. 


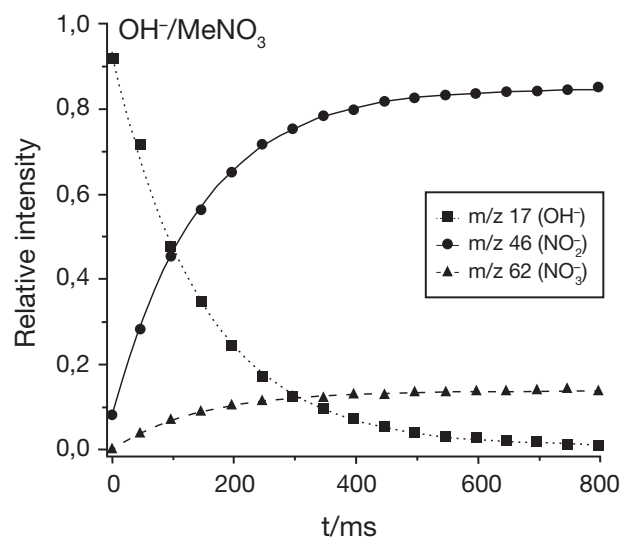

Figura 1.6 Cinética da reação do sistema $\mathrm{OH}^{-} / \mathrm{CH}_{3} \mathrm{ONO}_{2}$ obtida para uma pressão total de $1,8 \times 10^{-8}$ torr. $\mathrm{Na}$ ordenada, deve-se ler intensidade relativa (do inglês relative intensity) e, na abscissa, representa-se o tempo (ms). Figura adaptada de Correra e Riveros. ${ }^{69}$

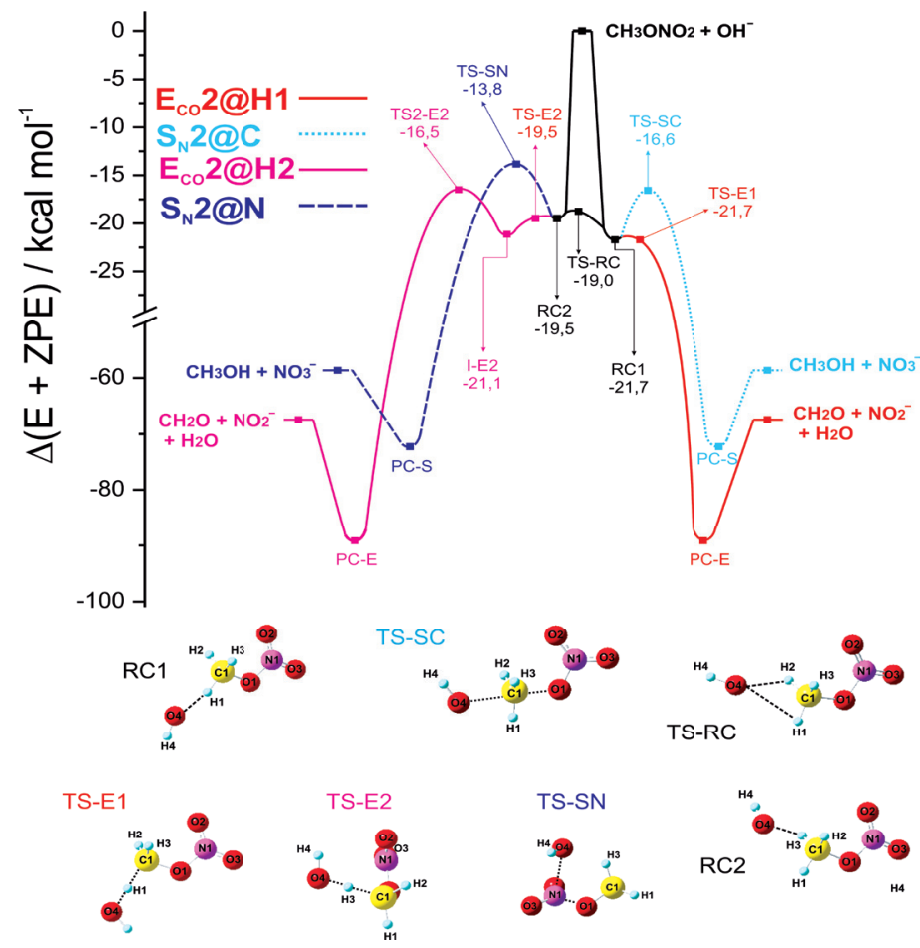

Figura 1.7 Lado esquerdo, diagrama de energia da reação $\mathrm{CH}_{3} \mathrm{ONO}_{2}+\mathrm{OH}^{-}$obtido com o método $\mathrm{CCSD}(\mathrm{T}) / \mathrm{CBS} / / \mathrm{MP} 2 / 6-311+\mathrm{G}(3 \mathrm{df}, 2 \mathrm{p})$. As energias dos pontos estacionários estão em $\mathrm{kcal} \mathrm{mol}^{-1}$ (ZPE está incluída), sendo relativas ao reagente $\left(0,0 \mathrm{kcal} \mathrm{mol}^{-1}\right)$. O complexo RC1

69 Id. ibid. 
está relacionado aos mecanismos $\mathrm{E}_{\mathrm{CO}} 2 @ \mathrm{H} 1$ e $\mathrm{S}_{\mathrm{N}} 2 @ \mathrm{C}$, enquanto $\mathrm{RC} 2$ deve ser associado aos mecanismos $\mathrm{E}_{\mathrm{CO}} 2 @ \mathrm{H} 2 \mathrm{e} \mathrm{S}_{\mathrm{N}} 2 @ \mathrm{~N}$. Lado direito, estruturas dos pontos estacionários principais.

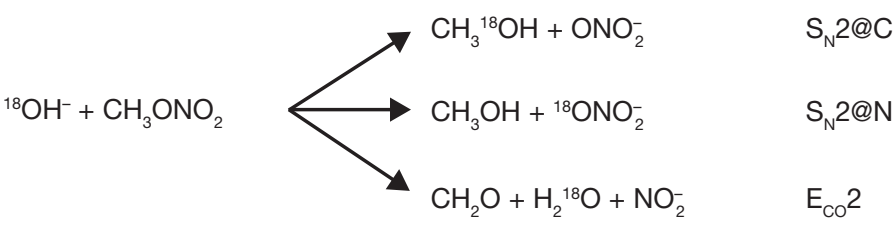

Esquema 1.1 Caminhos de reação entre ${ }^{18} \mathrm{OH}^{-}$e $\mathrm{CH}_{3} \mathrm{ONO}_{2}$ para o nucleófilo marcado isotopicamente.

\subsubsection{Resultados da superfície de energia potencial combinados com cálculos RRKM}

Uma melhor racionalização e compreensão dos resultados obtidos experimentalmente deve ser adquirida possivelmente com cálculos de estrutura eletrônica combinados com estimativas das constantes de velocidade. Para reações íon-molécula em fase gás, é bem comum a utilização da teoria $R R K M,{ }^{70}$ sendo que nessa aproximação o complexo dos reagentes é considerado uma molécula estável e que pode seguir um comportamento de reação unimolecular.

A caracterização da PES realizada com um método combinado de estrutura eletrônica de alto nível, CCSD(T)/CBS//MP2/6-311+G(3df,2p), se encontra na Figura 1.7. Uma característica da reação $\mathrm{CH}_{3} \mathrm{ONO}_{2}+\mathrm{OH}^{-}$é a elevada exotermicidade de todos os canais reacionais caracterizados, o que significa que o controle termodinâmico da seletividade pode ser ignorado.

De maneira geral, os resultados apresentados na Figura 1.7 mostram um acordo qualitativo entre os dados experimentais e as estimativas computacionais das barreiras. Os resultados experimentais mostram que os ataques nucleofílicos de $\mathrm{OH}^{-}$ao $\mathrm{CH}_{3} \mathrm{ONO}_{2}$ produziram os íons nitrito $\left(\mathrm{NO}_{2}^{-}\right)$e nitrato $\left(\mathrm{NO}_{3}^{-}\right)$nas proporções de 0,86 e 0,14 , respectivamente. Essa relação de produtos demonstra a maior preferência do canal de reação $\mathrm{E}_{\mathrm{CO}} 2$ com relação aos canais $\mathrm{S}_{\mathrm{N}} 2$ (no carbono e no nitrogênio). Os resultados computacionais sugerem que essa preferência é consequência de as barreiras de ativação dos canais de reação de eliminação $\left(\mathrm{E}_{\mathrm{CO}} 2 @ \mathrm{H} 1 \mathrm{e}\right.$ $\left.\mathrm{E}_{\mathrm{CO}} 2 @ \mathrm{H} 2\right)$ serem menores que aquelas observadas nos deslocamentos nucleofílicos.

A distribuição dos produtos $\left(\mathrm{NO}_{2}^{-}: \mathrm{NO}_{3}^{-}\right)$foi estimada a partir de cálculos RRKM das constantes de velocidade para cada caminho reacional. O primeiro resultado importante a partir desses cálculos é que as constantes de velocidade para os canais de eliminação são aproximadamente duas ordens de magnitude mais favoráveis do que os canais de substituição. Portanto, os cálculos RRKM indicam que a reação deve ocorrer por meio do mecanismo $\mathrm{E}_{\mathrm{CO}} 2 @ \mathrm{H} 1$, ou seja, 100\% do produto

70 Lourderaj e Hase (2009). 
$\mathrm{NO}_{2}^{-}$. Um esquema mais completo da cinética, como mostrado no Esquema 1.2, que permite a interconversão de RC1 e RC2, produz resultados semelhantes com ambos $\mathrm{RC} 1$ e RC2, favorecendo exclusivamente as vias de eliminação.
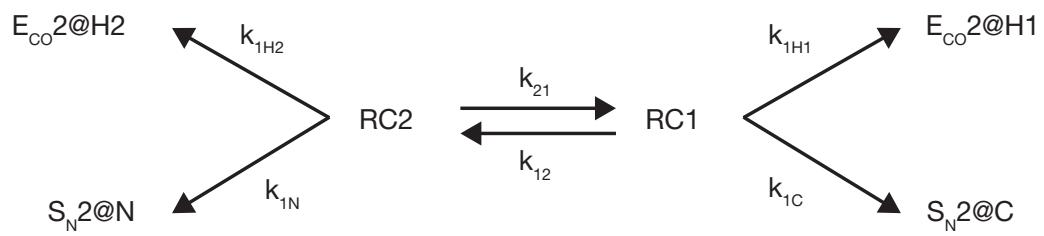

Esquema 1.2 Cinéticas completas das reações unimoleculares associadas aos vários canais provenientes dos complexos de reagentes RC1 e RC2.

Esse modelo cinético com as estimativas RRKM das constantes de velocidade se revela incapaz de descrever a proporção dos produtos observada experimentalmente. De fato, essa abordagem puramente estatística não descreve a razão de o caminho reacional $\mathrm{S}_{\mathrm{N}}$ 2@C ser observado experimentalmente. Além disso, a ausência do caminho $\mathrm{S}_{\mathrm{N}} 2 @ \mathrm{~N}$ é inexplicável, pois, de acordo com o perfil da PES, esse canal reacional tem barreira energética comparável à do canal $\mathrm{S}_{\mathrm{N}} 2 @ \mathrm{C}$. Daí a utilização de simulações de dinâmica direta desse sistema.

\subsubsection{Resultados das simulações BOMD}

O procedimento dinâmico empregado consistiu em realizar espalhamentos do nucleófilo $\mathrm{OH}^{-}$na espécie $\mathrm{CH}_{3} \mathrm{ONO}_{2}$, variando as energias de colisão e as orientações relativas dos dois fragmentos. As trajetórias simuladas foram iniciadas na região dos reagentes, isto é, $\mathrm{OH}^{-} \cdots \mathrm{CH}_{3} \mathrm{ONO}_{2}$ separados por uma distância grande o suficiente para as interações intermoleculares serem desprezíveis. A amostragem quase clássica, que inclui a ZPE, foi usada para selecionar as condições iniciais dos graus de liberdade vibracionais dos fragmentos $\mathrm{OH}^{-}$e $\mathrm{CH}_{3} \mathrm{ONO}_{2}$, sendo selecionadas a partir de suas distribuições de Boltzmann em $300 \mathrm{~K}$. A energia rotacional também foi considerada e selecionada a partir de suas distribuições de Boltzmann em $300 \mathrm{~K}$, considerando cada fragmento como um rotor rígido simétrico. Para a energia translacional relativa (energia de colisão, $E_{c o l}$ ) entre os fragmentos, foi considerado o valor de $1,0 \mathrm{kcal} \mathrm{mol}^{-1}$, consistente com a temperatura de $300 \mathrm{~K}$. Ao todo, foram simuladas 130 trajetórias, sendo propagadas por 2,0 ps. Em razão da demanda computacional, o método M062X/6-31+G(d) foi empregado nas simulações das trajetórias. No entanto, esse método passou por um processo de validação com relação ao método de referência CCSD(T)/CBS//MP2/6-311+G(3df,2p), conforme descrito anteriormente (subseção 1.3.4).

Apesar do pequeno número de trajetórias, ao todo, nas simulações, foram obtidas $74,3 \%$ de trajetórias com colisões reativas. Esse número é bastante satisfatório, o 
que conduz a uma eficiência de reação que suporta uma estatística significativa para a predição da seletividade. Experimentalmente, a proporção de produtos foi 0,86:0,14 $\left(\mathrm{NO}_{2}^{-}: \mathrm{NO}_{3}^{-}\right) .^{71} \mathrm{~A}$ proporção entre produtos $0,72: 0,28$ obtida nas simulações concorda relativamente bem com os resultados experimentais. Um resultado bastante satisfatório e surpreendente nas simulações foi a contribuição do canal de reação $\mathrm{S}_{\mathrm{N}} 2 @ \mathrm{~N}$ ser menor do que 4\%, o que é comparável com o limite de deteç̧ão experimental.

A dinâmica do sistema $\mathrm{CH}_{3} \mathrm{ONO}_{2}+\mathrm{OH}^{-}$é muito rica e diversificada. Ao examinar em detalhes o comportamento das trajetórias, encontra-se uma série de eventos bem distintos dinamicamente. Na Figura 1.8 estão classificadas as trajetórias simuladas quanto ao número de eventos importantes observados na dinâmica. Essa atribuição utilizada na classificação dos eventos dinâmicos das trajetórias observadas enfatiza os aspectos de comportamento fora das condições estatísticas desse sistema reacional.

De fato, a Figura 1.8 mostra um conjunto amplo de eventos em que se justifica um comportamento de natureza fora das condições estatísticas do sistema reacional $\mathrm{CH}_{3} \mathrm{ONO}_{2}+\mathrm{OH}^{-}$:

i. Em $21,5 \%$ das trajetórias foram observados espalhamentos reativos com apenas uma colisão;

ii. O número de recruzamentos de barreira é bastante significativo: ao todo, nas 130 trajetórias, foram observados 49 recruzamentos de barreira, todos associados ao mecanismo $\mathrm{E}_{\mathrm{CO}} 2$;

iii. Aproximadamente 64\% das trajetórias são classificadas como "complexo intermolecular", sendo " $<1$ ps", ou seja, um número significativo das trajetórias reativas levou poucos períodos vibracionais intermoleculares para formar os produtos.

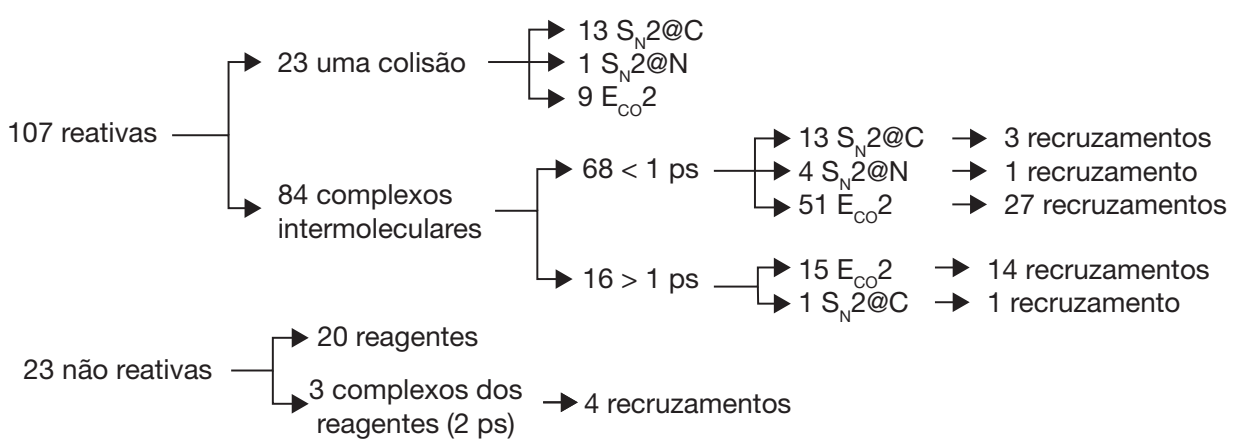

Figura 1.8 Distribuição das trajetórias reativas e não reativas, sendo as primeiras classificadas nos canais de reação caracterizados. Notação: "uma colisão" representa trajetórias que formam os produtos diretamente em um único evento de colisão; "complexo intermolecular" representa as trajetórias que levam pelo menos um período vibracional intermolecular para formar os produtos, sendo classificadas em " $<1$ ps" ou " $>1$ ps", ou seja, o tempo (maior ou menor que

71 Correra e Riveros (2010). 
1,0 ps) necessário para a formação dos produtos; "reagente" são trajetórias que voltam para os reagentes; "complexo reagente ( 2 ps)" são trajetórias que permaneceram na região do complexo dos reagentes por um período de 2,0 ps; e "recruzamento" representa o número total de ocorrência de recruzamento de barreira observado durante as trajetórias do canal especificado.

A Figura 1.9 ilustra trajetórias típicas observadas nas simulações para os canais de reação $\mathrm{S}_{\mathrm{N}} 2 @ \mathrm{C}, \mathrm{E}_{\mathrm{CO}} 2 @ \mathrm{H} 1, \mathrm{E}_{\mathrm{CO}} 2 @ \mathrm{H} 2$ e $\mathrm{S}_{\mathrm{N}} 2 @ \mathrm{~N}$. Nesta figura, estão representadas as dependências temporais de algumas distâncias relevantes no entendimento dinâmico dos mecanismos de reação. Além disso, "fotogramas", ou seja, as estruturas de eventos relevantes da dinâmica, são mostrados ao longo das trajetórias.

A Figura 1.9(i) descreve uma trajetória típica $\mathrm{S}_{\mathrm{N}} 2 @ \mathrm{C} . \mathrm{O}$ detalhe dinâmico em 970 fs mostra o evento da bipirâmide trigonal distorcida. Tal estrutura é encontrada comumente na descrição estática do TS associada ao mecanismo $\mathrm{S}_{\mathrm{N}} 2$. Além disso, essa mesma figura ilustra um recruzamento de barreira rápido (570 fs). De fato, na aproximação inicial dos fragmentos ocorrem três espalhamentos, com a diminuição gradativa da intensidade de espalhamento (acompanhar as variações de $\mathrm{C}-\mathrm{O}_{\mathrm{a}}$ no gráfico). No entanto, antes de o sistema passar pela barreira de ativação do canal de reação $\mathrm{S}_{\mathrm{N}} 2 @ \mathrm{C}$, ocorre uma abstração próton pelo nucleófilo, seguida rapidamente de um recruzamento.
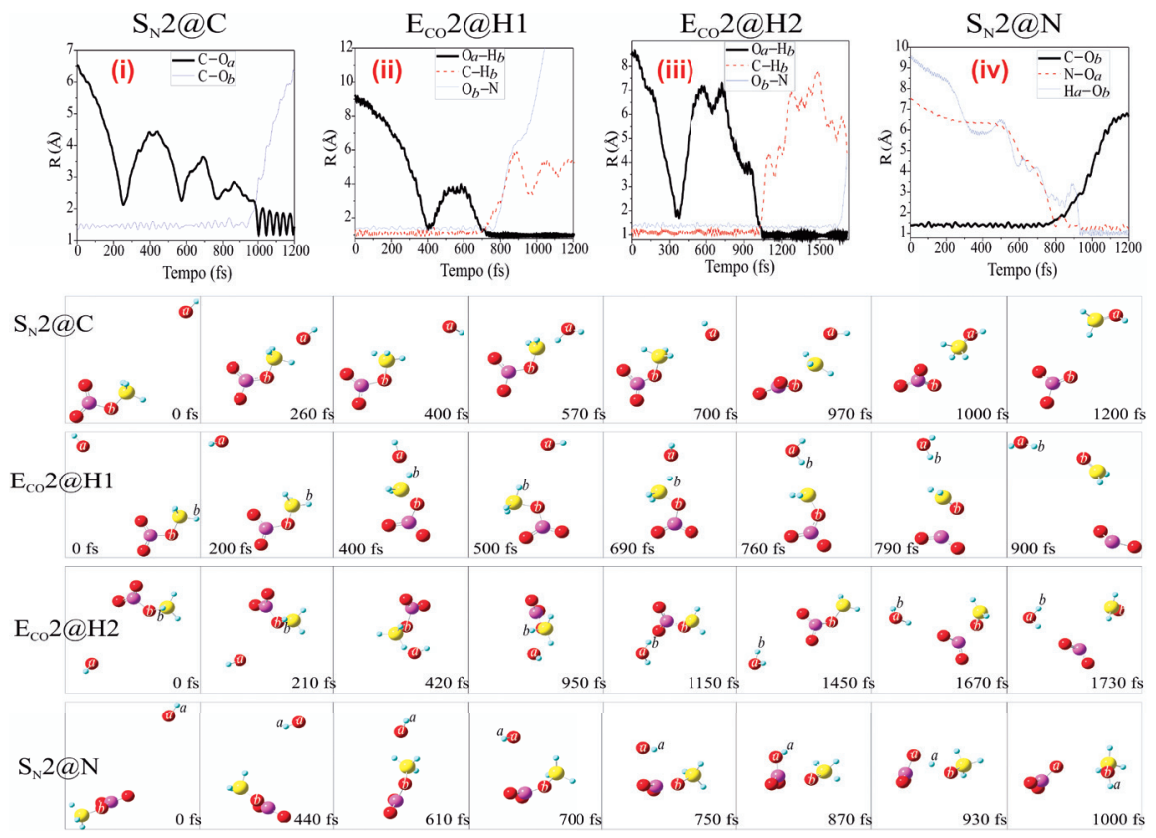

Figura 1.9 No painel superior: distâncias interatômicas relevantes em função do tempo de simulação para as trajetórias associados aos canais (i) $\mathrm{S}_{\mathrm{N}} 2 @ \mathrm{C}$, (ii) $\mathrm{E}_{\mathrm{CO}} 2 @ \mathrm{H} 1$, (iii) $\mathrm{E}_{\mathrm{CO}} 2 @ \mathrm{H} 2 \mathrm{e}$ (iv) $\mathrm{S}_{\mathrm{N}} 2 @ \mathrm{~N}$. No painel inferior: estruturas relevantes ao longo das trajetórias $\mathrm{S}_{\mathrm{N}} 2 @ \mathrm{C}, \mathrm{E}_{\mathrm{CO}} 2 @ \mathrm{H} 1$, $\mathrm{E}_{\mathrm{CO}} 2 @ \mathrm{H} 2$ e (iv) $\mathrm{S}_{\mathrm{N}} 2 @ \mathrm{~N}$. Os rótulos dos átomos encontram-se nas figuras do painel inferior. 
As figuras 1.9(ii) e (iii) retratam os mecanismos de reação rotulados no tra-

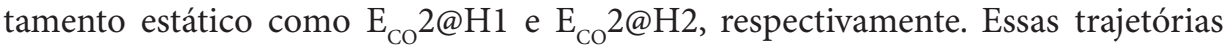
foram escolhidas para enfatizar os aspectos da natureza sincronizada e concertada desses mecanismos. Observe que os eventos reacionais do canal $\mathrm{E}_{\mathrm{CO}} 2 @ \mathrm{H} 1$ são mais rápidos do que os do canal $\mathrm{E}_{\mathrm{CO}} 2 @ \mathrm{H} 2$. Tais eventos estão relacionados com dois passos: a abstração de próton pelo nucleófilo e a fragmentação da ligação $\mathrm{N}-\mathrm{O}$ na espécie $\left[\mathrm{O}_{2} \mathrm{~N}-\mathrm{OCH}_{2}\right]^{-}$.

Por fim, a Figura 1.9(iv) ilustra a trajetória que produziu o produto associado ao canal $\mathrm{S}_{\mathrm{N}} 2 @ \mathrm{~N}$. Inicialmente, observa-se uma rotação da molécula $\mathrm{CH}_{3} \mathrm{ONO}_{2}$ para maximizar a atração entre o nucleófilo $\mathrm{OH}^{-}$e o grupo $-\mathrm{CH}_{3}$. Note que, no tratamento dinâmico, a conservação do momento angular conduz os fragmentos a uma geometria que se assemelha à estrutura RC2, que ocorre em $610 \mathrm{fs}$, e, em seguida, passa por uma estrutura similar ao TS-SN, em 700 fs. Por fim, uma rotação interna da porção $\mathrm{OH}^{-}$, durante um período de $\sim 100 \mathrm{fs}$, culmina com a transferência de próton e a dissociação nos produtos (metanol e íon nitrato).

Uma questão importante no sistema reacional $\mathrm{CH}_{3} \mathrm{ONO}_{2}+\mathrm{OH}^{-}$está na seletividade $\mathrm{S}_{\mathrm{N}} 2 @ \mathrm{C}: \mathrm{S}_{\mathrm{N}} 2 @ \mathrm{~N}$, observada nos experimentos e suportada pelas simulações BOMD. A racionalização dos resultados obtidos nas simulações pode ser atribuída a duas contribuições distintas: (i) o controle dinâmico exercido pelas interações eletrostáticas de longo alcance; e (ii) o comportamento fora das condições estatísticas que privilegia o canal de reação $\mathrm{S}_{\mathrm{N}} 2 @ \mathrm{C}$ em detrimento do $\mathrm{S}_{\mathrm{N}} 2 @ \mathrm{~N}$.

O mapa do potencial eletrostático do nitrato de metila está ilustrado na Figura 1.10. Deve-se notar que o potencial eletrostático perto do átomo de nitrogênio é, relativamente, mais positivo do que aquele observado no átomo de carbono. No entanto, o potencial altamente positivo no átomo de nitrogênio é blindado por um potencial eletrostático muito mais negativo gerado pelos átomos de oxigênio. Essa blindagem eletrostática gerada pelos átomos de oxigênio se torna importante em regiões de longo alcance, o que pode ser observado em "cortes" do mapa do potencial eletrostático do nitrato de metila (Figura 1.10). Portanto, essa proteção eletrostática deve restringir as possibilidades do ataque nucleofílico ao átomo de nitrogênio.

Portanto, como consequência do controle dinâmico exercido pelas interações eletrostáticas de longo alcance, as trajetórias são induzidas, no movimento inicial de aproximação dos fragmentos, a provocar um espalhamento inicial na região da metila. No entanto, se, por um lado, esse efeito eletrostático diminui a possibilidade de deslocamento nucleofílico no átomo de nitrogênio, por outro lado, deve ativar significativamente o canal de reação $\mathrm{S}_{\mathrm{N}} 2 @ \mathrm{C}$. 

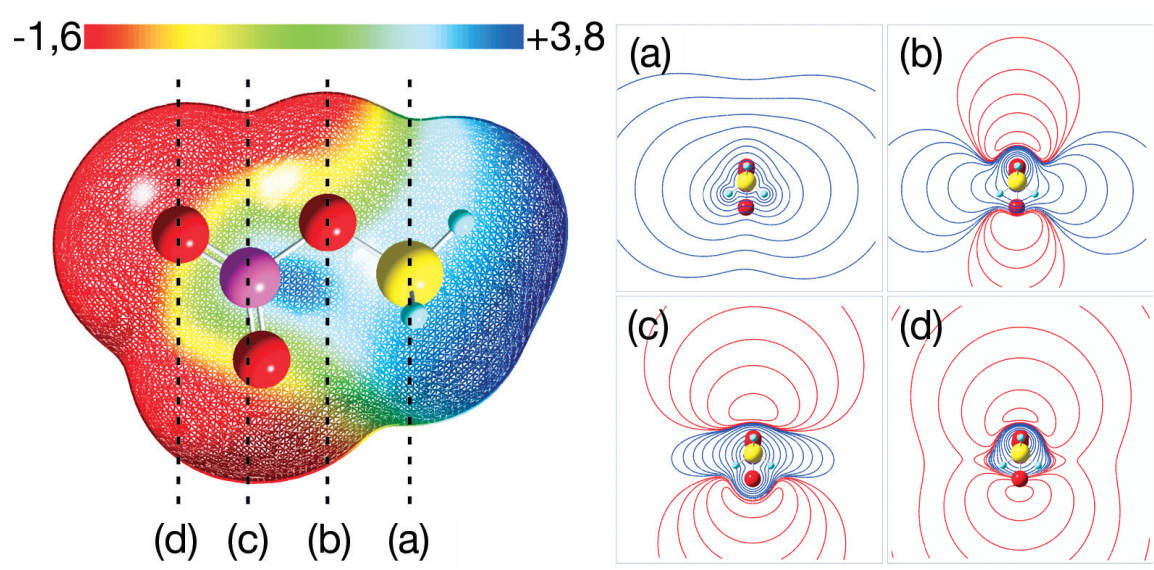

Figura 1.10 Representação do potencial eletrostático de nitrato de metila calculado com o método MP2/6-311+G(3df,2p). No lado direito, (a), (b), (c) e (d) são gráficos de contorno do potencial eletrostático sobre os planos que passam através do átomo de carbono, oxigênio $(\mathrm{N}-\mathrm{O}-\mathrm{C})$, nitrogênio e oxigênio (terminal), respectivamente. Os "cortes" do potencial eletrostático são perpendiculares em relação ao plano de simetria da molécula.

\subsubsection{Comportamento fora das condições estatísticas na reação $\mathrm{CH}_{3} \mathrm{ONO}_{2}+\mathrm{OH}^{-}$}

$\mathrm{Na}$ reação $\mathrm{CH}_{3} \mathrm{ONO}_{2}+\mathrm{OH}^{-}$, a proporção dos produtos, observada experimentalmente, não é descrita adequadamente pela teoria RRKM. De fato, as simulações BOMD produziram uma proporção $\mathrm{S}_{\mathrm{N}} 2 @ \mathrm{C}: \mathrm{E}_{\mathrm{CO}} 2: \mathrm{S}_{\mathrm{N}} 2 @ \mathrm{~N}$, que está em boa concordância com os resultados experimentais. A partir da observação das trajetórias, acredita-se que a falha da abordagem estatística RRKM é consequência de uma combinação de fatores: (i) o controle do potencial eletrostático gerado pelos átomos de oxigênio do grupo $\mathrm{ONO}_{2}$; (ii) reagentes complexos ( $\mathrm{RC} 1$ e RC2) aparentemente não equilibrados; (iii) um número excessivo de recruzamentos de barreira; e (iv) um número considerável de trajetórias diretas (sem a formação do complexo de reagente), isto é, o complexo produto é obtido a partir de apenas uma colisão.

\subsubsection{Conclusão e perspectivas}

As simulações de dinâmica direta, particularmente BOMD, tratada neste capítulo, têm fornecido um entendimento mais completo dos eventos em escala atômico-molecular de mecanismos e seletividades de reações, o que inclui processos unimoleculares, bimoleculares e eventos que ocorrem após o estado de transição, entre outros.

A metodologia dinâmica fornece uma visão mais completa, pois sonda outras regiões da $\mathrm{PES}$ que praticamente não são consideradas na metodologia convencional 
da química computacional (varredura na superfície de energia potencial, na busca por pontos estacionários, combinada com estimativas das constantes de velocidade com base em aproximações estatísticas) no estudo de reações. Assim, a dinâmica descreve os efeitos da superfície de energia potencial e aspectos intrínsecos da dinâmica (a conservação do momento angular, os efeitos associados à energia cinética e a transferência de energia intermolecular e intramolecular). De fato, a aplicação de métodos dinâmicos se torna indispensável para sistemas reacionais que apresentam comportamentos fora das condições estatísticas.

O futuro das simulações de dinâmica direta focará certamente na exatidão, bem como na possibilidade de tratar sistemas cada vez maiores e reações mais complexas. Contudo, para realizar tais avanços, serão necessários a popularização, o desenvolvimento e o aprimoramento de aspectos estratégicos, entre os quais se destacam:

i) A possibilidade de realizar dinâmica direta com métodos de estrutura eletrônica de alto nível, principalmente envolvendo estados excitados e interseções cônicas. No entanto, para isso, torna-se essencial o desenvolvimento de processadores (CPU) de alto desempenho mais poderosos, assim como programas e linguagens de programação científica que acompanhem a evolução desses processadores. Nesse ponto, o conceito CUDA (plataforma de computação paralela) tem se destacado nos últimos anos; $; 2$

ii) O tratamento mais apropriado de alguns efeitos intrínsecos da mecânica quântica, os quais não são considerados na dinâmica direta quase clássica, tais como: interferências entre trajetórias e trocas quantizadas de energia entre os graus de liberdade. Alguns avanços têm sido realizados no tratamento da ZPE. ${ }^{73}$

\section{REFERÊNCIAS}

Allen, M. P.; Tisdesley, D. J. Computer simulation of liquids. Oxford: Clarendon Press, 1991. Ammal, S. C.; Yamataka, H.; Aida, M.; Dupuis, M. Dynamics-driven reaction pathway in an intramolecular rearrangement. Science, 299, p. 1555-1557, 2003.

Anslyn, E. V.; Dougherty, D. A. Modern physical organic chemistry. Sausalito: University Science Book, 2006.

BaChrach, S. M. Computational organic chemistry. Nova York: John Wiley \& Sons, 2007. BAeR, T.; Hase, W. L. Unimolecular reaction dynamics: theory and experiments. 2. ed. Nova York: Oxford University Press, 1999.

72 Wolf (2010).

73 Guo, Thompson e Sewell (1996). 
Bakken, V.; Millam, J. M.; Schlegel, H. B. Ab initio classical trajectories on the Born-Oppenheimer surface: updating methods for Hessian-based integrators. J. Chem. Phys., 111 , p. 8773-8777, 1999.

Blais, N. C.; Bunker, D. L. Monte Carlo calculations. II. The reactions of alkali atoms with methyl iodide. J. Chem. Phys., 37, p. 2713-2720, 1962.

Bolton, K.; Hase, W. L.; Peslherbe, G. H. Direct dynamics simulations of reactive systems. In: Thompson, D. L. (Ed.). Modern methods for multidimensional dynamics computations in chemistry. Londres: World Scientific, 1998. p. 143-189.

Bornemann, F. A.; Schütte, C. A mathematical investigation of the Car-Parrinello method. Numer. Math., 78, p. 359-376, 1998.

Bueker, H.-H.; Helgaker, T.; Ruud, K.; Uggerud, E. Energetics and dynamics of intermolecular proton-transfer processes. 2. Ab initio direct dynamics calculations of the reaction $\mathrm{H}_{3} \mathrm{O}^{+}+\mathrm{NH} 3 \rightarrow \mathrm{NH}^{+}+\mathrm{H} 2 \mathrm{O}$. J. Phys. Chem., 100, p. 15388-15392, 1996.

Bunker, D. L. Monte Carlo calculation of triatomic dissociation rates. I. N2O and O3. J. Chem. Phys., 37, p. 393-403, 1962.

. Classical trajectory methods. Methods Comput. Phys., 10, p. 287-325, 1971.

CAR, R.; DE Angelis, F.; Giannozzi, P.; MARZARI, N. First-principles molecular dynamics. In: YiP, S. (Ed.). Handbook of materials modeling. Amsterdã: Springer, 2005. v. I, p. 59-76.

CAR, R.; PARrinello, M. Unified approach for molecular dynamics and density-functional theory. Phys. Rev. Lett., 55, p. 2471-2474, 1985.

Carpenter, B. K. Intramolecular dynamics for the organic chemist. Acc. Chem. Res., 25, p. $520-528,1992$.

. Dynamic behavior of organic reactive intermediates. Angew. Chem. Int. Ed., 37, p. 3340-3350, 1998.

. Nonexponential decay of reactive intermediates: new challenges for spectroscopic observation, kinetic modeling and mechanistic interpretation. J. Phys. Org. Chem., 16, p. 858-868, 2003.

. Nonstatistical dynamics in thermal reactions of polyatomic molecules. Annu. Rev. Phys. Chem., 56, p. 57-89, 2005.

Chabinyc, M. L.; Craig, S. L.; Regan, C. K.; Brauman, J. I. Gas-phase ionic reactions: dynamics and mechanism of nucleophilic displacements. Science, 279, p. 1882-1886, 1998.

Correra, T. C.; Riveros, J. M. Gas-phase nucleophilic and elimination reactions in simple alkyl nitrates. J. Phys. Chem. A, 114, p. 11910-11919, 2010.

CrAmer, C. J. Essentials of computational chemistry: theory and models. 2. ed. Chichester: Wiley, 2004.

De SouzA, M. A. Estudo computacional de dinâmica de reações químicas. Recife: UFPE, 2012. 
De Souza, M. A.; Correra, T. C.; Riveros, J. M.; Longo, R. L. Selectivity and mechanisms driven by reaction dynamics: the case of the gas-phase $\mathrm{OH}^{-}+\mathrm{CH} 3 \mathrm{ONO} 2$ reaction. J. Am. Chem. Soc., 134, p. 19004-19010, 2012.

Dykstra, C.; Frenking, G.; Kim, K.; Scuseria, G. (Ed.). Theory and applications of computational chemistry: the first forty years. Amsterdã: Elsevier, 2005.

Frenkel, D.; Smit, B. Understanding molecular simulation: from algorithms to applications. Londres: Academic Press, 2002.

GAO, J. Methods and applications of combined quantum mechanical and molecular mechanical potentials. In: Lipkowitz, K. B.; Boyd, D. B. Reviews in computational chemistry. Nova York: John Wiley \& Sons, 1996. v. 7, p. 119-185.

GARGANO, R. Superfície de energia potencial: conexão entre a estrutura eletrônica e a dinâmica molecular. In: Santos, H. F.; Coura, P. Z.; Dantas, S. O.; Barone, P. M. (Ed.). Escola brasileira de estrutura eletrônica. 1. ed. São Paulo: Livraria da Física, 2003. p. 38-66.

GEAR, C. W. Numerical initial value problems in ordinary differential equations. Englewood Cliffs: Prentice Hall, 1971.

Gibson, D. A.; Ionova, I. V.; CARter, E. A. A comparison of Car-Parrinello and Born-Oppenheimer generalized valence bond molecular dynamics. Chem. Phys. Lett., 240, p. 261-267, 1995.

Glowacki, D. R.; Marsden, S. P.; Pilling, M. J. Significance of nonstatistical dynamics in organic reaction mechanisms: time-dependent stereoselectivity in cyclopentyne-alkene cycloadditions. J. Am. Chem. Soc., 131, p. 13896-13897, 2009.

Goldman, L. M.; Glowacki, D. R.; Carpenter, B. K. Nonstatistical dynamics in unlikely places: $[1,5]$ hydrogen migration in chemically activated cyclopentadiene. J. Am. Chem. Soc., 133, p. 5312-5318, 2011.

Gunaydin, H.; Houk, K. N. Molecular dynamics simulation of the HOONO decomposition and the HO•/NO2• Caged radical pair in water. J. Am. Chem. Soc., 130, p. 1003610037, 2008.

Guo, Y.; Thompson, D. L.; Sewell, T. D. Analysis of the zero-point energy problem in classical trajectory simulations. J. Chem. Phys., 104, p. 576-582, 1996.

Hamaguchi, M.; Nakaishi, M.; Nagai, T.; Nakamura, T.; Abe, M. Notable effect of an electron-withdrawing group at $\mathrm{C} 3$ on the selective formation of alkylidenecyclobutanes in the thermal denitrogenation of 4-spirocyclopropane-1-pyrazolines. Nonstatistical dynamics effects in the denitrogenation reactions. J. Am. Chem. Soc., 129, p. 12981-12988, 2007. Hase, W. L. Simulations of gas-phase chemical reactions: applications to SN2 nucleophilic substitution. Science, 266, p. 998-1002, 1994.

Hase, W. L.; Buckowski, D. G. Monte Carlo sampling of a microcanonical ensemble of classical harmonic oscillators. Chem. Phys. Lett., 74, p. 284-287, 1980.

. Dynamics of ethyl radical decomposition. II. Applicability of classical mechanics to large-molecule unimolecular reaction dynamics. J. Comput. Chem., 3, p. 335-343, 1982. 
Hase, W. L.; Duchovic, R. J.; Hu, X.; Komornicki, A.; Lim, K. F.; Lu, D. H. et al. Venus. Quantum Chemistry Program Exchange Bulletin, 16, p. 671, 1996.

Helgaker, T.; Uggerud, E.; Jensen, H. J. Integration of the classical equations of motion on ab initio molecular potential energy surfaces using gradients and hessians: application to translational energy release upon fragmentation. Chem. Phys. Lett., 173, p. 145-150, 1990.

Henriksen, N. E.; Hansen, F. Y. Theories of molecular reaction dynamics: the microscopic foundation of chemical kinetics. Nova York: Oxford University Press, 2008.

Hirst, D. M. Potential energy sufarces: molecular structure and reaction dynamics. Londres: Taylor and Francis, 1985.

Jensen, F. Introduction to computational chemistry. 2. ed. Chichester: Wiley, 2007.

Kuo, I.-F. W.; Mundy, C. J.; McGrath, M. J.; Siepmann, J. I. Time-dependent properties of liquid water: a comparison of Car-Parrinello and Born-Oppenheimer molecular dynamics simulations. J. Chem. Theory Comput., 2, p. 1274-1281, 2006.

Liu, J.; Song, K.; Hase, W. L.; Anderson, S. L. Direct dynamics trajectory study of vibrational effects: can polanyi rules be generalized to a polyatomic system? J. Am. Chem. Soc., 126, p. 8602-8603, 2004.

López, J. G.; Vayner, G.; Lourderaj, U.; Addepalli, S. V.; Kato, S.; de Jong, W. A. et al. A direct dynamics trajectory study of $\mathrm{F}^{-}+\mathrm{CH} 3 \mathrm{OOH}$ reactive collisions reveals a major non-IRC reaction path. J. Am. Chem. Soc., 129, p. 9976-9985, 2007.

LourderaJ, U.; Hase, W. L. Theoretical and computational studies of non-RRKM unimolecular dynamics. J. Phys. Chem. A, 113, p. 2236-2253, 2009.

Lourderaj, U.; Song, K.; Windus, T. L.; Zhuang, Y.; Hase, W. L. Direct dynamics simulations using hessian-based predictor-corrector integration algorithms. J. Chem. Phys., 126, p. 044105-1-044105-11, 2007.

Manikandan, P.; Zhang, J.; Hase, W. L. Chemical dynamics simulations of $\mathrm{X}^{-}+\mathrm{CH} 3 \mathrm{Y}$ $->\mathrm{XCH} 3+\mathrm{Y}^{-}$gas-phase SN2 nucleophilic substitution reactions. Nonstatistical dynamics and nontraditional reaction mechanisms. J. Phys. Chem. A, 116, p. 3061-3080, 2012.

Mann, D. J.; Hase, W. L. Ab initio direct dynamics study of cyclopropyl radical ring-opening. J. Am. Chem. Soc., 124, p. 3208-3209, 2002.

Marx, D.; Hutter, J. Ab initio molecular dynamics: theory and implementation. Cambridge: Cambridge University Press, 2009.

Maseras, F.; Morokuma, M. IMOMM - A new integrated ab-initio plus molecular mechanics geometry optimization scheme of equilibrium structures and transition-states. J. Comput. Chem., 16, p. 1170-1179, 1995.

Mikosch, J.; Trippel, S.; Eichhorn, C.; Otto, R.; Lourderaj, U.; Zhang, J. X. et al. Imaging nucleophilic substitution dynamics. Science, 319, p. 183-186, 2008.

Millam, J. M.; Bakken, V.; Chen, W.; Hase, W. J.; Schlegel, H. B. Ab initio classical trajectories on the Born-Oppenheimer surface: hessian-based integrators using fifth-order polynomial and rational function fits. J. Chem. Phys., 111, p. 3800-3805, 1999. 
Morgon, N. H.; Coutinho, K. (Ed.). Métodos de química teórica e modelagem molecular. São Paulo: Livraria da Física, 2008.

Murrell, J. N.; Carter, S.; Farantos, S. C.; Huxley, P.; Varandas, A. J. Molecular potential energy functions. Chichester: Wiley, 1984.

ÖHrn, Y.; Deumens, E. Towards an ab initio treatment of the time-dependent Schrödinger equation of molecular systems. J. Phys. Chem. A, 103, p. 9545-9551, 1999.

Paranjothy, M.; Sun, R.; Zhuang, Y.; Hase, W. L. Direct chemical dynamics simulations: coupling of classical and quasiclassical trajectories with electronic strucuture theory. Interdisciplinary Reviews: Computational Molecular Science, 3, p. 296-316, 2012.

Peslherbe, G. H.; Wang, H.; Hase, W. L. Unimolecular dynamics of $\mathrm{Cl}^{-}$...CH3Cl intermolecular complexes formed by $\mathrm{Cl}^{-}+\mathrm{CH} 3 \mathrm{Cl}$ association. J. Chem. Phys., 102, p. 5626$5635,1995$.

Monte Carlo sampling for classical trajectory simulations. In: Ferguson, D. M.; Siepmann, J. I.; Truhlar, D. G. (Ed.). Advances in chemical physics: Monte Carlo methods in chemical physics. Nova York: Wiley, 1999. v. 105, p. 171-202.

Polanyi, J. C.; Zewail, A. H. Direct observation of the transition state. Acc. Chem. Res., 28, p. 119-132, 1995.

Press, W. H.; Teukolsky, S. A.; Vetterling, W. T.; Flannery, B. P. Numerical recipes in fortran: the art of scientific computing. Cambridge: University Press, 1992.

Quijano, L. M.; Singleton, D. A. Competition between reaction and intramolecular energy redistribution in solution: observation and nature of nonstatistical dynamics in the ozonolysis of vinyl ethers. J. Am. Chem. Soc., 133, p. 13824-13827, 2011.

Rehbein, J.; CARPenter, B. K. Do we fully understand what controls chemical selectivity? Phys. Chem. Chem. Phys., p. 20906-20922, 2011.

Riveros, J. M.; Maria José, S.; Takashima, K. Gas-phase nuclephilic displacement reactions. In: Gold, V.; Bethell, D. (Ed.). Advances in physical organic chemistry. Londres: Academic Press, 1985. v. 21, p. 197-240.

Rossi, I.; TRuhlar, D. G. Parameterization of NDDO wavefunctions using genetic algorithms. An evolutionary approach to parameterizing potential energy surfaces and direct dynamics calculations for organic reactions. Chem. Phys. Lett., 233, p. 231-236, 1995.

Schwegler, E.; Grossman, J. C.; Gygi, F.; Galli, G. Towards an assessment of the accuracy of density functional theory for first principles simulations of water. II. J. Chem. Phys., 121, p. 5400-5409, 2004.

Sibert, E. L.; Reinhardt, W. P.; Hynes, J. T. Intramolecular vibrational relaxation and spectra of $\mathrm{CH}$ and $\mathrm{CD}$ overtones in benzene and perdeuterobenzene. J. Chem. Phys., 81, p. 1115-1134, 1984.

Singleton, D. A.; Hang, C.; Szymanski, M. J.; Greenwald, E. E. A new form of kinetic isotope effect: dynamic effects on isotopic selectivity and regioselectivity. J. Am. Chem. Soc., 125, p. 1176-1177, 2003. 
STOCK, G.; Müller, U. Flow of zero-point energy and exploration of phase space in classical simulations of quantum relaxation dynamics. J. Chem. Phys., 111, p. 65-76, 1999.

Stoer, J.; Bulirsch, R. Introduction to numerical analysis. Nova York: Springer-Verlag, 1980.

Sun, L.; Hase, W. L. Born-Oppenheimer direct dynamics classical trajectory simulations. In: Lipkowitz, K. B.; LARTER, R.; CUndARI, T. R. (Ed.). Reviews in computational chemistry. Hoboken: John Wiley \& Sons, 2003. v. 19, p. 79-146.

. Ab initio direct dynamics trajectory simulation of $\mathrm{C} 2 \mathrm{H} 5 \mathrm{~F}->\mathrm{C} 2 \mathrm{H} 4+\mathrm{HF}$ product energy partitioning. J. Chem. Phys., 121, p. 8831-8845, 2004.

Sun, L.; Hase, W. L.; Song, K. Trajectory studies of SN2 nucleophilic substitution. 8. Central barrier dynamics for gas phase $\mathrm{Cl}^{-}+\mathrm{CH} 3 \mathrm{Cl}$. J. Am. Chem. Soc., 123, p. 5753-5756, 2001.

Sun, L.; SonG, K.; HASE, W. L. SN2 reaction that avoids its deep potential energy minimum. Science, 296, p. 875-878, 2002.

Svensson, M.; Humbel, S.; Froese, R. D.; Matsubara, T.; Sieber, S.; Morokuma, K. ONIOM: a multi-layered integrated $\mathrm{MO}+\mathrm{MM}$ method for geometry optimizations and single point energy predictions. A test for Diels-Alder reactions and $[\mathrm{Pt}(\mathrm{P}(\mathrm{t}-\mathrm{Bu}) 3) 2]+\mathrm{H} 2$ oxidative addition. J. Phys. Chem., 100, p. 19357-19363, 1996.

Szabo, A.; Ostlund, N. S. Modern quantum chemistry: introduction to advanced eletronic structure theory. Nova York: Dover, 1989.

TAngney, P. On the theory underlying the Car-Parrinello method and the role of the fictitious mass parameter. J. Chem. Phys., 124, p. 044111-1-044111-14, 2006.

Tangney, P.; Scandolo, S. How well do Car-Parrinello simulations reproduce the Born-Oppenheimer surface? Theory and examples. J. Chem. Phys., 116, p. 14-24, 2002.

Trout, B. L. Car-Parrinello methods in chemical engineering: their scope and potential. In: WEI, J.Advances in Chemical Engineering. San Diego: Academic Press, v. 28, p. 353-397, 2001.

Uggerud, E.; Helgaker, T. Dynamics of the reaction $\mathrm{CH}_{2} \mathrm{OH}^{+}-->\mathrm{CHO}^{+}+\mathrm{H} 2$. Translational energy release from ab initio trajectory calculations. J. Am. Chem. Soc., 114, p. $4265-$ 4268, 1992.

Wang, I. S.; Karplus, M. Dynamics of organic reactions. J. Am. Chem. Soc., 95, p. 8160$8164,1973$.

Wolf, L. K. The GPU revolution. Chemical \& Engineering News, 88, p. 27-29, 2010.

WyAtT, R. E.; IUng, C.; LeForestier, C. Quantum dynamics of overtone relaxation in benzene. II. 16 mode model for relaxation from CH(v=3). J. Chem. Phys., 97, p. 3477-3486, 1992. 